Christian Hoffmann, Joris Weigert, Erik Esche, Jens-Uwe Repke

\title{
A pressure-driven, dynamic model for distillation columns with smooth reformulations for flexible operation
}

Journal article | Accepted manuscript (Postprint)

This version is available at https://doi.org/10.14279/depositonce-10464

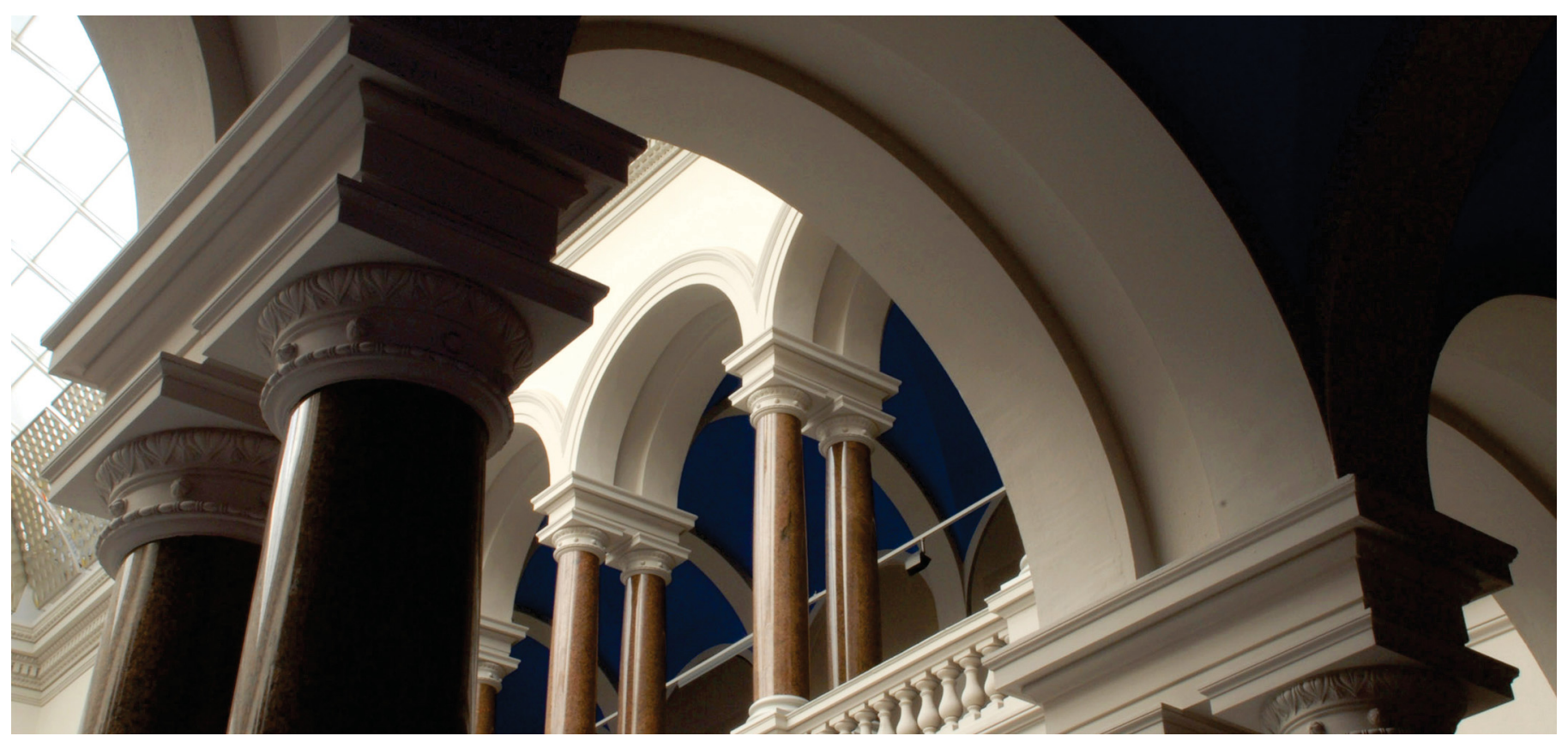

Hoffmann, C., Weigert, J., Esche, E., \& Repke, J.-U. (2020). A pressure-driven, dynamic model for distillation columns with smooth reformulations for flexible operation. Computers \& Chemical Engineering, 107062. https://doi.org/10.1016/j.compchemeng.2020.107062 
Accepted Manuscript of: Hoffmann, C., Weigert, J., Esche, E., \& Repke, J.-U. (2020). A pressure-driven, dynamic model for distillation columns with smooth reformulations for flexible operation. Computers \& Chemical Engineering, 107062. https://doi.org/10.1016/j.compchemeng.2020.107062

(c) 2019 This manuscript version is made available under the CC-BY-NC-ND 4.0 license (http://creativecommons.org/licenses/by-nc-nd/4.0/).

\title{
A pressure-driven, dynamic model for distillation columns with smooth reformulations for flexible operation
}

\author{
Christian Hoffmann ${ }^{\mathrm{a}, *}$, Joris Weigert ${ }^{\mathrm{a}}$, Erik Esche ${ }^{\mathrm{a}}$, Jens-Uwe Repke ${ }^{\mathrm{a}}$ \\ ${ }^{a}$ Technische Universität Berlin, Process Dynamics and Operations Group, Sekr. KWT 9, \\ Straße des 17. Juni 135, Berlin 10623, Germany
}

\section{Abstract}

Dynamic models for plants including the startup or shutdown phase are still scarce as the (dis-)appearence of phases or streams is challenging to implement. We present an approach to model a distillation column, in which these operation modes are also considered without exchanging equations. For this purpose, the well-known modeling equations for distillation columns are reformulated robustly to allow for the disappearance of the vapor phase without discontinuities. The reformulation does not depend on solving an optimization problem and could easily be applied to other column types or different unit operations. The proposed model is solved in two case studies with 10 and 40 trays, respectively. In these case studies, the influence of single phenomena on the obtained dynamic profiles is investigated, e.g., weeping, which are often neglected. The proposed modeling approach yields a dynamic model that can be solved without reinitialization for a realistically

\footnotetext{
*Corresponding author

Email addresses: c.hoffmann@tu-berlin.de (Christian Hoffmann), joris.weigert@tu-berlin.de (Joris Weigert), erik.esche@tu-berlin.de (Erik Esche), j.repke@tu-berlin.de (Jens-Uwe Repke)
} 
large number of trays.

Keywords: Pressure-driven modeling, dynamic modeling, distillation column, startup operation

\section{Introduction}

While steady-state models for distillation columns are state-of-the-art in industry and academia, there are many applications in which these steadystate models are insufficient, such as optimal control or state estimation, column startup and shutdown, transition between operation points, batch distillation, controller design or controller tuning, and safety-related events, e.g., reboiler/condenser failure or activation of pressure relief valves. There is also a trend towards higher flexibility in the chemical industry due to volatile market developments and demand (Seifert et al., 2014), hence studying both design and its impact on plant dynamics and operation becomes more and more important.

In spite of these many possible applications and challenges, the number of publications on the issue is still small, which may be attributed to the complexity of these transient periods and the occuring time-discrete events, e.g., (dis-)appearing phases, trays filling up, streams beginning to flow as soon as a certain level is reached (e.g., the flow over a weir). Nevertheless, some authors have suggested dynamic models for distillation columns. Gani et al. (1986), Cameron et al. (1986), and Ruiz et al. (1988) suggested a dynamic model for distillation columns, which was able to describe column startup. They solved the describing ordinary differential equations (ODEs) with implicit integration methods while determining the algebraic or proce- 
dural variables based on a case-dependent task sequence. Gonzalez-Velasco et al. (1987) suggested improvements in batch distillation startup based on a model with many simplifying assumptions, in which the challenges of appearing phases were not discussed. Albet et al. (1994) published a dynamic model for startup, in which equations were switched as soon as certain criteria are met, e.g., the reboiler reaches the boiling temperature. Flender et al. (1998) and Flender (1998) also developed modeling approaches for column startup but neglected the transition from an empty column until the startup of the reboiler. This approach was extended by Wang et al. (2003) for batch distillation. A similar approach was also taken by Elgue et al. (2004). Wendt et al. (2003) investigated this approach for continuous heat-integrated distillation while Tran et al. (2002) looked at distillation columns with liquid-liquid phase separation whereas Reepmeyer et al. (2003, 2004) and Forner et al. (2008) studied reactive distillation columns with trays and packings. Their models also considered the aforementioned transition phase. Staudt et al. (2007) also investigated the startup of reactive distillation columns. Staak et al. (2011) used a dynamic model to assess safety hazards in distillation columns. Recently, Kender et al. (2019) also presented a dynamic, pressure-driven model for a packing column.

The models presented in (Wang et al., 2003; Reepmeyer et al., 2004; Forner et al., 2008) are formulated based on if-else conditions. In addition, equations are exchanged during the dynamic simulation, e.g., when the bubble point is reached. This has several drawbacks, e.g., the Jacobian changes structurally during the integration and the discontinuity of first and second order derivatives may hinder convergence or require repeated re-initialization 
at these switching points. In addition, such approaches are infeasible for application in simultaneous optimization approaches, in which the dynamic system is fully discretized over a finite time horizon. In contrast, we present an approach without the necessity to switch equations during the numerical integration of the system by using smooth reformulations of $\mathrm{min} / \mathrm{max}$ operators and step functions, see for example (Duran, 1984). This contribution addresses two main goals:

1. It shows how dynamic models for distillation columns may be formulated when these columns are not at their nominal operating points due to increased flexible operation or undesired operating modes, such as reboiler/condenser failure or the opening of safety valves. This is currently rarely done. Instead, the nominal design is chosen so that undesired phenomena, such as weeping, do not occur.

2. It demonstrates the capabilities of sigmoidals to model the (dis-)appearence of phases within a process unit; an approach that can easily be applied on other phase equilibria, such as liquid-liquid or solid-liquid.

Ideas close in spirit to our approach were presented by Gopal and Biegler (1999) and Lang and Biegler (2002) but while they used these reformulations to smooth the complementarity conditions in their optimization problem, we directly reformulate the modeling equations. Non-smooth approaches for this modeling problem have, for example, been taken by Sahlodin et al. (2016).

In the following, we will briefly discuss the fundamentals of distillation to describe the relevant phenomena within a distillation column, Section 3 discusses our modeling approach, and Section 4 contains the case studies to demonstrate the model's performance. 


\section{Distillation fundamentals}

In this section, the three phases of column startup in distillation are discussed and the basic scheme of a tray within a distillation column is sketched to point out the considered phenomena. These phenomena are discussed in more detail in Section 3.

\subsection{Three phases during column startup}

Ruiz et al. (1988) defined three phases of column startup:

1. The discontinuous phase: In this phase, hydraulic variables experience drastic changes while thermodynamic variables remain almost constant.

2. The semi-continuous phase: Here, drastic changes appear for thermodynamic variables due to the formation of phase equilibria. Hydraulic variables hardly change during this phase.

3. The continuous phase: In this phase, the column operates at steadystate and must only react to small disturbances.

Based on the three phases assigned here, we would also like to consider a fourth phase:

4. The full-discontinuity phase: At the beginning of this phase, the feed flow is turned off, reboiler duty is reduced, and the column operates at total reflux. As the vapor flow disappears, both thermodynamic and hydraulic variables may experience drastic changes simultaneously.

This fourth phase is included to account for several operating modes: First of all, the shutdown could be of high interest when modeling batch processes in multi-purpose plants. The model could be used to reduce downtime periods. 
Table 1: Notation of streams and equipment in Figure 1.

\begin{tabular}{|c|c|}
\hline Number & Explanation \\
\hline (1) & Vapor outlet from tray $t \mathrm{~B}$ \\
\hline & Liquid outlet from tray $t$ due to entrainment \\
\hline (3) & Liquid inlet from the tray above $\mathrm{A}$ due to weeping \\
\hline (4) & Flow over the weir from tray $t-1$ \\
\hline & Liquid outlet from downcomer $\mathrm{D}$ into tray $t$ \\
\hline (6) & Vapor inlet from tray $t+1 \mathrm{C}$ \\
\hline (7) & Liquid inlet due to entrainment \\
\hline 8 & Liquid outlet due to weeping \\
\hline \multirow[t]{4}{*}{ (9) } & Liquid outlet from tray $t$ over the weir into downcomer \\
\hline & below E \\
\hline & Feed \\
\hline & Heat loss \\
\hline
\end{tabular}

The phase is also relevant when modeling safety risks, e.g., condenser/reboiler failure. The fourth phase may hence not be entered on purpose but as a result of failing equipment.

\subsection{Fluid dynamics on a tray}

There are many possible streams to consider when modeling a distillation column in addition to the conventional and idealized assumption of only one vapor and one counter-current liquid stream. Figure 1 shows the scheme of the considered streams in this contribution, in which circled numbers represent streams and squares represent equipment sections. Their explanation 
is given in Table 1. Certain effects are still neglected here, e.g., a possible vapor flow through the downcomer. We will focus on the others as they were deemed the most relevant during column startup and shutdown and to stay within scope. Certainly, the model will be extended to the other phenomena in the future.

\subsection{Phenomena}

The phenomena modeled in this work are only briefly discussed in this section and the units of the expressions are not given. Instead, the reader is referred to the literature. Stichlmair $(2010 \mathrm{a}$ b $)$ and Green and Perry $(2007)$ give extensive overviews on distillation in general. Zuiderweg (1982) summarizes research on sieve trays. In addition, Gani et al. (1986) summarize several relevant equations from the literature to model the phenomena described in the following. In the model discussed below, all equations were adapted with consistent units as given in the supplementary material. These phenomena are seldom implemented in dynamic or even steady-state models. However, to perform the tasks outlined in the introduction, it is important to consider them.

Flow over weir: The liquid flow over the weir is typically expressed as a function of the height over the weir $h_{\mathrm{ow}}$, which will be discussed further below. We use the formulation by Bennett et al. (1983), which also considers the froth density in combination with the weir parameter in Green and Perry (2007, p.14-44).

$$
V_{\text {weir }}^{L, \text { flow }}=\rho_{\text {froth }} \cdot L_{\text {weir }} \cdot\left(\frac{h_{\mathrm{ow}}}{0.664}\right)^{\frac{3}{2}}
$$




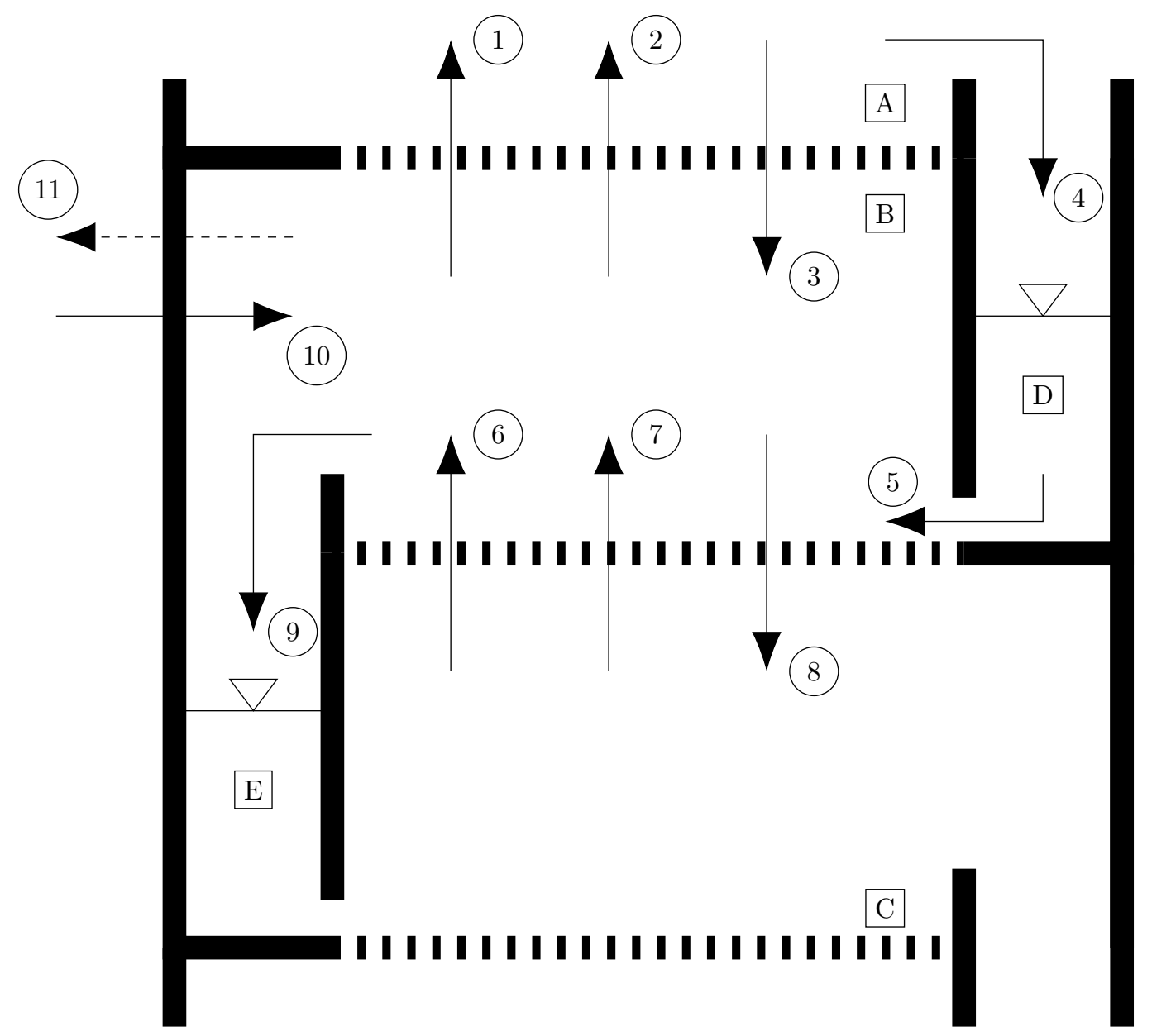

Figure 1: Scheme of a tray within a tray column with in- and outgoing flows. Numbers and letters are explained in Table 1 
The expression yields the volume flow of liquid over the weir $V_{\text {weir }}^{L, \text { flow }}$ as a function of the froth density $\rho_{\text {froth }}$, the weir length $L_{\text {weir }}$, and the liquid height over the weir.

Weeping: Weeping appears when liquid droplets start to flow through the holes of a tray in case the vapor velocity is too low. This causes back-mixing and hence reduces separation efficiency. Wijn (1998) introduced a weeping

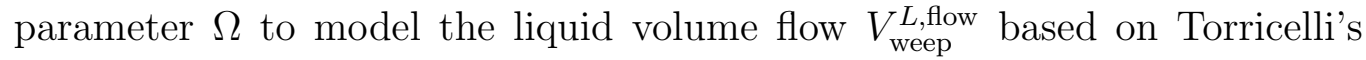
law:

$$
V_{\text {weep }}^{L, \text { flow }}=\Omega \cdot A_{\text {active }} \cdot \varphi \cdot \sqrt{2 \cdot g \cdot h_{\mathrm{cl}}}
$$

Therein, $A_{\text {active }}$ is the active area of the column, $\varphi$ is the free-area ratio of the column, $g$ is the gravitational acceleration, and $h_{\mathrm{cl}}$ is the height of the clear liquid on a tray. Staak et al. (2011) measured the weeping parameter and regressed parameters for the following expression, which depends on the free-area ratio and the $\mathrm{F}$ factor (gas load):

$$
\Omega=\min \left(1 ; C_{3} \exp \left(-C_{2} \frac{F}{\varphi}+C_{1}\right)\right)
$$

Hoffmann et al. (2020) approximated this expression smoothly by using the numerical expressions given in Section 2.4.

Thermodynamic efficiency: Thermodynamic efficiency of a tray can be described with the well known Murphree efficiency, which correlates the actual concentration change on a tray with the maximum change if thermodynamic equilibrium is achieved. Using the relationship of Lewis (1936), Murphree efficiencies can be determined via the overall efficiency $E_{\text {column, }}$, the slope of the equilibrium curve $m$, and the ratio of vapor and liquid flow Chan and 
Fair, 1984a):

$$
E=\frac{x_{t}^{V}-x_{t+1}^{V}}{x_{t}^{V, e q u i}-x_{t+1}^{V}}=\frac{\lambda^{E_{\mathrm{column}}}-1}{\lambda-1},
$$

where

$$
\begin{gathered}
\lambda=m \frac{F^{V}}{F^{L}}, \\
m=\frac{\alpha}{\left(1+(\alpha-1) x_{c=1}^{L}\right)^{2}}, \\
\alpha=\frac{P_{c=1}^{V L}}{P_{c=2}^{V L}} .
\end{gathered}
$$

Therein, $c=1$ indicates the low-boiling component and $P_{c}^{V L}$ is the vapor pressure of component $c$ (thermodynamic ideality is assumed). Although we limit ourselves to binary systems in this work, Chan and Fair (1984b) also proposed a formulation for multicomponent systems.

Liquid entrainment: Liquid entrainment appears when the vapor velocity is so large that shear forces pull the liquid upwards. This also causes backmixing and hence reduces separation efficiency. Hunt et al. (1955) found a correlation between the entrained liquid mass flow and the vapor mass flow depending on parameters $a$ and $b$, the surface tension $\sigma$, the superficial velocity $w^{V}$, and the height over the bubbling zone, which depends on tray spacing $H$ and the height of the clear liquid:

$$
\frac{F^{L, \mathrm{E}} \cdot M^{L}}{F^{V} \cdot M^{V}}=a \frac{1}{\sigma}\left(\frac{w^{V}}{H-2.5 \cdot h_{\mathrm{cl}}}\right)^{b} .
$$

Downcomer level and liquid outlet: The outlet volume flow of a downcomer $V^{L, \text { flow }}$ is correlated to the head loss under the downcomer apron, i.e., (Green 
and Perry, 2007, p. 14-44):

$$
h_{d c}^{\text {flow }}=165.2 \cdot\left(\frac{V^{L, \text { flow }}}{A_{\text {dc }}}\right)^{2} .
$$

Therein, $A_{\mathrm{dc}}$ is the area under the downcomer apron.

\subsection{Numerical expressions}

To model the discontinuities apperaing during startup or continuous operation, $\max / \min$ operators or step functions are used. Examples of such discontinuities are the liquid outlet of a tray as described by the Francis weir equation or the formation of a new phase. As max operators or switches are non-differentiable at their switching point, they can either not be used in conjunction with many solvers or their application results in the necessity of continuous re-initialization. Instead, we apply smoothing techniques for these functions. Whenever an operator is mentioned in Section 3, it is reformulated by using the expressions below. Figure 2 compares these approximations with true max operators and step functions.

Balakrishna and Biegler (1992) showed that the max operator can be approximated with

$$
\Theta=\max (x, 0) \approx \frac{x+\sqrt{x^{2}+\epsilon}}{2}
$$

where $\epsilon$ is a small positive number. This reformulation is applied whenever necessary.

A switch function or sigmoidal characterizes the activation of a discrete phenomenon, e.g., the formation of a phase. A sigmoidal $\theta$ is the derivative of the max operator $\Psi$ with respect to its argument $x$, hence:

$$
\theta=\frac{\mathrm{d} \Theta}{\mathrm{dx}} \approx 0.5\left(1+\frac{x}{\sqrt{x^{2}+\epsilon}}\right) .
$$




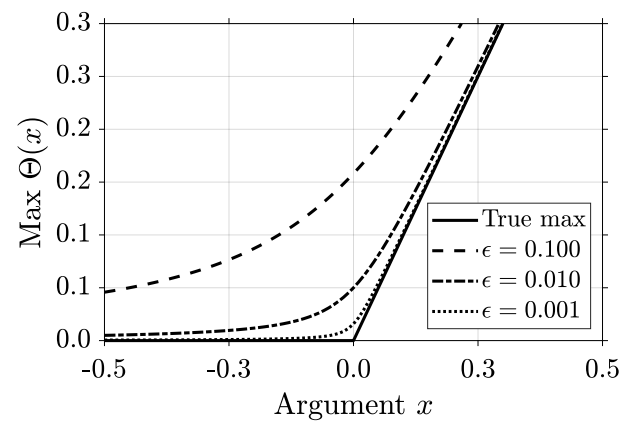

(a) Max operator.

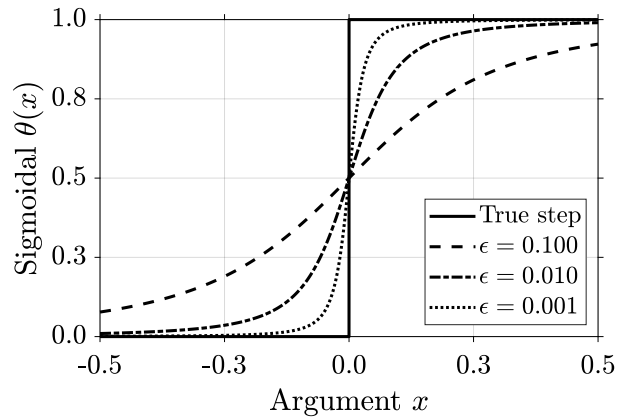

(b) Sigmoidal function.

Figure 2: Max operator and sigmoidal functions with their smooth approximations.

\section{Column Model}

This section presents the modeling equations. As many of these equations are well known, we will only point out the relevant equations subject to reformulation. The whole model is available as supplementary material. Figure 3 and Figure 4 illustrate the control volumes in this work and the assumed geometry: A tray column with segmented weirs and an internal reboiler is assumed. This reboiler type is selected as it represents the simplest setup. The geometric parameters indicated in these figures will be discussed in the upcoming sections.

\subsection{Condenser}

The following assumptions are made for the condenser:

- The condenser is assumed to be at steady-state;

- The dynamics of the internal energy are neglected because of the low sensitivity of liquid enthalpy with respect to temperature;

- The liquid is sub-cooled by $\Delta T_{\mathrm{CON}}$; 


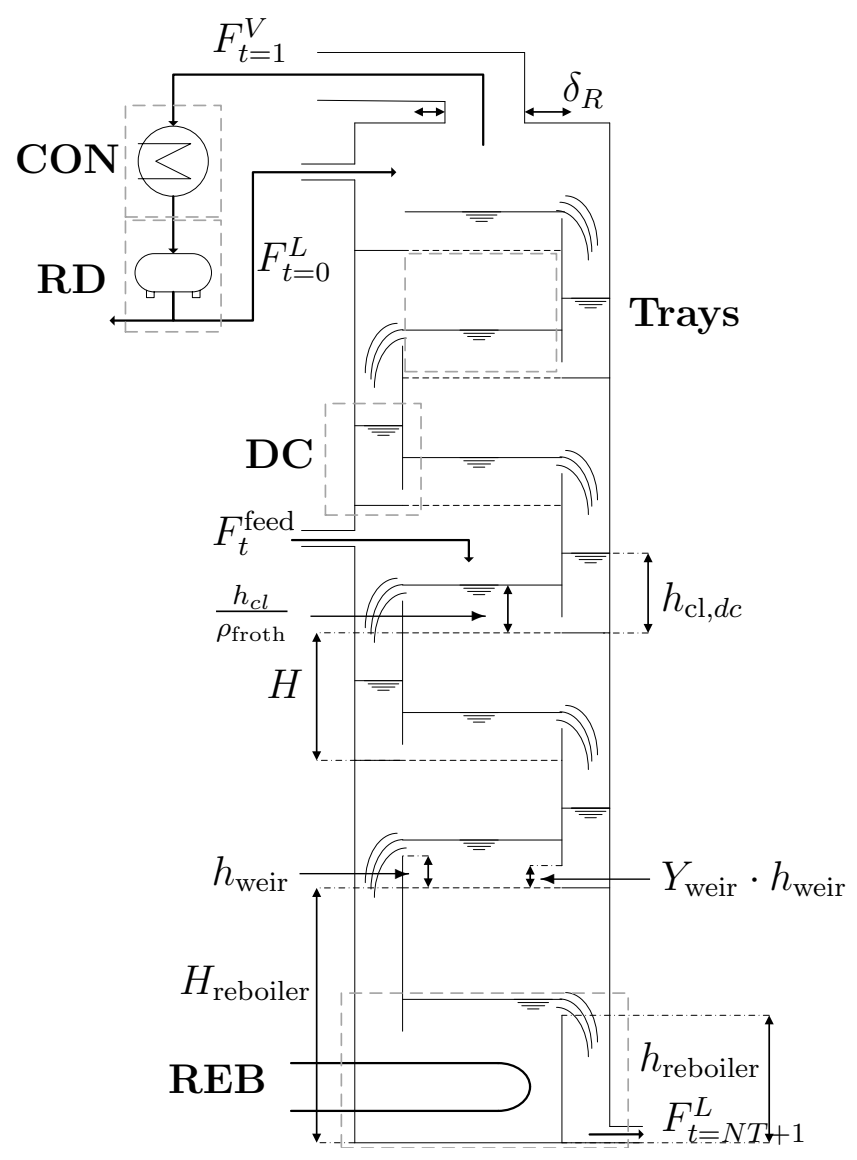

Figure 3: Assumed geometry of the distillation column, gray dashed lines depict the control volumes of this work's model; $\mathrm{CON}=$ condenser, $\mathrm{RD}=$ reflux drum, $\mathrm{DC}=$ downcomer, $\mathrm{REB}=$ reboiler 


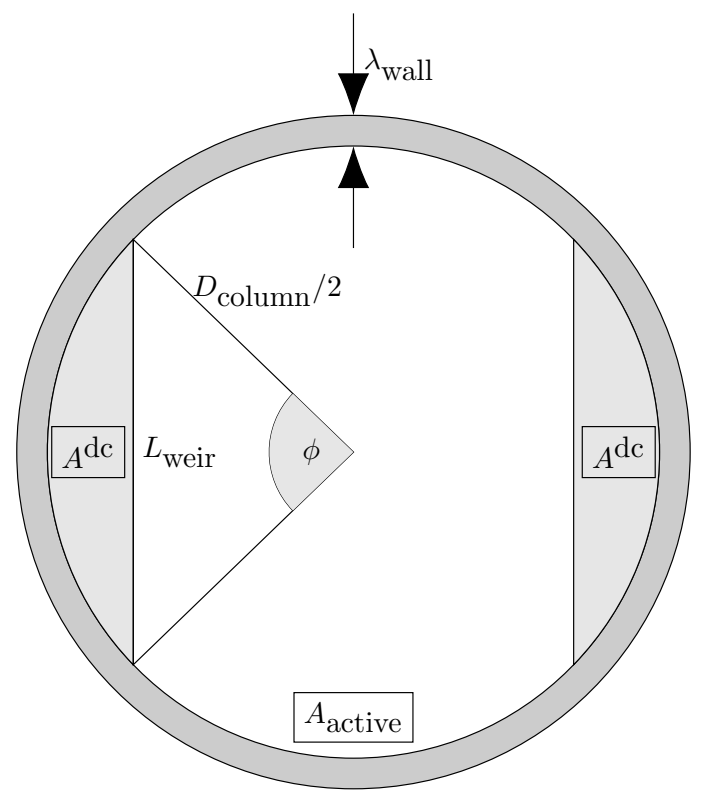

Figure 4: Geometric parameters of the tray. $D^{\text {column }}$ : Column diameter; $L_{\text {weir }}$ : Weir length; $A^{\mathrm{dc}}$ : Downcomer area; $A_{\text {active }}$ : Active area; $\lambda_{\text {wall }}$ : Wall thickness.

Balances: The condenser consists of the mole balance and the energy balance:

$$
0=F_{t=1}^{V}+F_{t=1}^{L, \mathrm{E}}-F_{\mathrm{CON}}^{L}
$$

and

$$
0=Q_{\mathrm{CON}}+F_{t=1}^{V} \cdot h_{t=1}^{V}+F_{t=1}^{L, \mathrm{E}} \cdot h_{t=1}^{L}-F_{\mathrm{CON}}^{L} \cdot h_{t=0}^{L} .
$$

Therein, $F_{t=1}^{V}$ and $F_{t=1}^{L, \mathrm{E}}$ are the vapor stream and the liquid stream due to entrainment from the first tray and $F_{\mathrm{CON}}^{L}$ is the liquid outlet stream. The energy balance contains the enthalpies of the respective streams and the condenser duty.

Composition: The condenser temperature is computed from thermodynamic equilibrium for a total condenser and allowing for a subcooling of $\Delta T_{\mathrm{CON}}$. 
The liquid enthalpy is calculated at the temperature in subcooled state. However, inlet mole fraction will be zero as long as there is no vapor flow from the trays. This would result in infeasible solutions for both temperature and heat duty. Therefore, we compute the composition of the condenser effluent:

$$
x_{\mathrm{CON}, c}=\psi_{t=1} \cdot\left(\Phi \cdot x_{t=1, c}^{V}+(1-\Phi) \cdot x_{t=1, c}^{L}\right)+\left(1-\psi_{t=1}\right) \cdot \sum_{t=1}^{N T} x_{t, c}^{\mathrm{feed}} \cdot y_{t}^{\mathrm{feed}}
$$

The outlet composition will be equal to the feed composition as long the sigmoidal $\psi_{t=1}$ has not switched to one. The variable $y_{t}^{\text {feed }}$ is a parameter describing the feed tray, i.e., it is 1 for a feed tray and 0 otherwise. The variable $\Phi$ is the phase fraction of the vapor in the mixture of vapor and entrained liquid:

$$
\left(F_{t=1}^{V}+F_{t=1}^{L, \mathrm{E}}\right) \cdot \Phi=F_{t=1}^{V}
$$

\subsection{Reflux drum}

The following assumptions are made for the reflux drum:

- The energy balance is neglected;

- The molar enthalpy of the liquid outlet is set to $h_{t=0}^{L}$;

- The molar volume of the liquid is constant;

- The liquid in the reflux drum is ideally mixed.

The model of the reflux drum contains the dynamic molar component balance:

$$
\frac{\mathrm{d} H U_{\mathrm{RD}, c}}{\mathrm{dt}}=F_{\mathrm{CON}}^{L} \cdot x_{\mathrm{CON}, c}-F_{t=0}^{L} \cdot x_{t=0, c}^{L}-F_{\mathrm{dist}} \cdot x_{t=0, c}^{L}
$$


Controllers: The outlet streams for the distillate

$$
F_{\text {dist }}=\left(F_{\text {dist }}^{\mathrm{SP}}+K_{\text {dist }} \cdot\left(L_{\mathrm{RD}}^{L}-L_{\mathrm{RD}}^{L, \mathrm{SP}}\right)\right) \cdot \gamma_{\mathrm{RD}}
$$

and the reflux

$$
F_{t=0}^{L}=\left(F_{t=0}^{L, \mathrm{SP}}+K_{t=0} \cdot\left(T_{t=\mathrm{tCtrlRD}}-T_{t=\mathrm{tCtrlRD}}^{\mathrm{SP}}\right) \cdot \Upsilon\right) \cdot \gamma_{\mathrm{RD}}
$$

are used for controlling the level in the reflux drum $L_{\mathrm{RD}}^{L}$ and the temperature $T_{t=\text { tCtrlRD }}$, respectively. The tray, which is used for reflux control, must be determined via a sensitivity analysis. Both controllers have a feed-forward value (superscript SP), which maintains the steady-state. We apply P controllers as the possible steady-state offset is not relevant for the taken modeling approach in this work. As activating the controllers rightaway would result in an infeasible solution as the reflux drum is empty and its level would become negative in this instance. Consequently, control is activated with the sigmoidal $\gamma_{\mathrm{RD}}$ as soon as the level reaches a minimum value $L_{\mathrm{RD}}^{\min }$ :

$$
\gamma_{\mathrm{RD}}=\frac{1}{2}+\frac{1}{2} \cdot \frac{L_{\mathrm{RD}}^{L}-L_{\mathrm{RD}}^{\min }}{\sqrt{\left(L_{\mathrm{RD}}^{L}-L_{\mathrm{RD}}^{\min }\right)^{2}+(10)^{-10}}}
$$

The parameter $\Upsilon$ activates or deactivates control and will be discussed further in the simulation studies.

Volume and level: The liquid volume in the reflux drum $V_{\mathrm{RD}}^{L}$ is coupled to the holdup via the density. The correlation between volume and level is a nonlinear equation containing an arccosine. As in (Hoffmann et al., 2020), we approximate this relation with a cubic polynomial:

$$
V_{\mathrm{RD}}^{L}=V A_{\mathrm{RD}} \cdot\left(L_{\mathrm{RD}}^{L}\right)^{3}+V B_{\mathrm{RD}} \cdot\left(L_{\mathrm{RD}}^{L}\right)^{2}+V C_{\mathrm{RD}} \cdot L_{\mathrm{RD}}^{L} .
$$

The parameters $V A_{\mathrm{RD}}$ to $V C_{\mathrm{RD}}$ must be regressed for the given geometry of the reflux drum. 


\subsection{Trays}

The following assumptions are made for the trays:

- Both liquid and vapor phase are ideally mixed;

- Fluid and tray material have the same temperature;

- The molar volume of the liquid is constant;

- The inert gas within the column during startup (or later) is neglected;

- The involved components form an ideal mixture for the sake of simplicity.

Mole balance and equilibrium: The tray model contains a dynamic mole balance, which includes a few more terms than the conventional one:

$$
\begin{aligned}
\frac{\mathrm{d} H U_{t, c}}{\mathrm{dt}} & =F_{t}^{\text {feed }} \cdot x_{t, c}^{\mathrm{feed}} \cdot y_{t}^{\mathrm{feed}} \\
& +\underbrace{y_{\mathrm{CON}, t} \cdot\left(F_{t=0}^{L}+(1-\Upsilon) \cdot F_{\text {dist }}\right) \cdot x_{t=0, c}^{L}}_{\text {from reflux drum }} \\
& +\underbrace{\left(1-y_{\mathrm{CON}, t}\right) \cdot\left(F_{t-1}^{L, \text { weep actual }} \cdot x_{t-1, c}^{L}+F_{d c=t-1}^{L, \text { actual }} \cdot x_{d c=t-1, c}^{L}-F_{t}^{L, \text { back,actual }} \cdot x_{t, c}^{L}\right)}_{\text {weeping from above, flow from downcomer, backflow into downcomer }} \\
& +\underbrace{F_{t+1}^{V} \cdot x_{t+1, c}^{V}+F_{t+1}^{L, \mathrm{E}} \cdot x_{t+1, c}^{L}-\left(F_{\text {weir }, t}^{L}+F_{t}^{L, \text { weep }, \text { actual }}\right) \cdot x_{t, c}^{L}-F_{t}^{V} \cdot x_{t, c}^{V}-F_{t}^{L, \mathrm{E}} \cdot x_{t, c}^{L}}_{\text {in- and outlet vapor streams, entrained liquid, weeping outlet, and liquid flow over the weir }} \cdot
\end{aligned}
$$

The second term also contains the distillate flow in case $\Upsilon$ is zero (total reflux). The expressions for the flow from the previous downcomer and the backflow into the downcomer are discussed in the downcomer section. 
The thermodynamic equilibrium determines the vapor composition at equilibrium for the given tray temperature:

$$
x_{t, c}^{V \text {,equi }}=x_{t, c}^{L} \cdot \frac{P_{t, c}^{V L}\left(T_{t}\right)}{P_{t}}
$$

Therein, $P_{t, c}^{V L}$ is the vapor pressure of component $c$ and $P_{t}$ is the pressure on tray $t$.

Energy balance: In addition, to the flows considered in the mole balance, the dynamic energy balance contains a term for heat loss:

$$
\begin{aligned}
\frac{\mathrm{d} U_{t}}{\mathrm{dt}}= & -Q_{t}^{\mathrm{loss}}+F_{t}^{\mathrm{feed}} \cdot h_{t}^{\text {feed }} \cdot y_{t}^{\text {feed }}+y_{\mathrm{CON}, t} \cdot\left(F_{t=0}^{L}+(1-\Upsilon) \cdot F_{\mathrm{dist}}\right) \cdot h_{t=0}^{L} \\
& +\left(1-y_{\mathrm{CON}, t}\right) \cdot\left(F_{t-1}^{L, \text { weep }} \cdot h_{t-1}^{L}+F_{d c=t-1}^{L, \text { actual }} \cdot h_{t-1}^{L}-F_{t}^{L, \text { back,actual }} \cdot h_{t}^{L}\right) \\
& +F_{t+1}^{V} \cdot h_{t+1}^{V}+F_{t+1}^{L, \mathrm{E}} \cdot h_{t+1}^{L}-\left(F_{\text {weir }, t}^{L}+F_{t}^{L, \text { weep }, \text { actual }}\right) \cdot h_{t}^{L}-F_{t}^{V} \cdot h_{t}^{V}-F_{t}^{L, \mathrm{E}} \cdot h_{t}^{L}
\end{aligned}
$$

The internal energy $U_{t}$ is here defined as:

$$
U_{t}=H U_{t}^{L} \cdot h_{t}^{L}+H U_{t}^{V \text {,actual }} \cdot h_{t}^{V}-P_{t} \cdot V^{\text {tray }} \cdot(10)^{2}+\underbrace{m^{\text {tray }} \cdot c^{\text {tray }} \cdot\left(T_{t}-T_{\text {ref }}\right)}_{\text {share of tray material }} .
$$

Fluid dynamics: The computation of the pressure drop is based on the work of Bennett et al. (1983). By coupling of vapor flow and pressure drop, the vapor flow becomes pressure-driven:

$$
\begin{aligned}
\Delta P_{t}^{\text {tray }}= & \underbrace{\left(\operatorname{sign}_{t} \cdot \frac{\xi}{2} \cdot\left(F_{t}\right)^{2}+\rho_{t-1}^{L} \cdot g \cdot h_{\mathrm{cl}, t-1}\right) \cdot 10^{-5} \cdot\left(1-y_{\mathrm{CON}, t}\right)}_{\text {pressure drop on every tray but the first }} \\
& +\underbrace{\operatorname{sign}_{t} \cdot\left(128 \cdot \frac{\nu \cdot F_{t}^{V} \cdot v_{t}^{V} \cdot L_{\text {tube }}}{\pi \cdot\left(\delta_{\text {tube }}\right)^{4}}+3 \cdot 8 \cdot \xi_{\text {corner }} \cdot \frac{\rho_{t}^{V}}{\left(\delta_{\text {tube }}\right)^{4}} \cdot\left(\frac{F_{t}^{V} \cdot v_{t}^{V}}{\pi}\right)^{2}\right) \cdot 10^{-5} \cdot y_{\mathrm{CON}, t}}_{\text {pressure drop between first tray and condenser }}
\end{aligned}
$$


The pressure drop between trays considers both dry and wet pressure drop. The dry pressure drop is a function of a drag coefficient $\zeta$ and the squared gas load factor $F_{t}$ while the wet pressure depends on both liquid density $\rho_{t-1}^{L}$ and height of clear liquid $h_{\mathrm{cl}, t-1}$ on the tray above, as well as gravitational acceleration.

The pressure drop between first tray and condenser contains terms for the pipe flow and the repeated redirection. Assuming laminar flow, the drag coefficient is $64 / R e$. Canceling the respective terms leads to an expression, which depends on kinematic viscosity $\nu$, vapor flow from tray $t$, molar volume $v_{t}^{V}$, the length of the tube between column and condenser $L_{\text {tube }}$, and its diameter $\delta_{\text {tube }}$. Concerning the redirections, (Beek et al., 1999, p. 69) give values for various geometries and their respective drag coefficients $\zeta_{\text {corner }}$, including elbows. Three redirections are assumed: directly at the top, downward the column, and towards the condenser. The pressure drop also contains a sign function, which is a sigmoidal switching from -1 to 1 at zero. With this term, it is, in principle, possible to model vapor backflow. However, vapor backflow was not observed under the investigated scenarios within this work:

$$
\operatorname{sign}_{t}=\frac{F_{t}^{V}}{\sqrt{\left(F_{t}^{V}\right)^{2}+(10)^{-8}}}
$$

The height above the weir $h_{\mathrm{ow}, t}$ is a function of the height of the clear liquid $h_{\mathrm{cl}, t}$ and the weir height $h_{\mathrm{weir}}$ :

$$
h_{\mathrm{cl}, t}=\rho_{\text {froth }, t} \cdot\left(h_{\text {weir }}+h_{\text {ow }, t}\right)
$$

Froth density is calculated as a function of the gas load. As discussed in (Hoffmann et al. 2020), $h_{\mathrm{ow}, t}$ may become negative if the liquid holdup on a tray is too small, which would cause Equation (1) to yield numerical errors. 
We therefore apply a smooth max operator on the height above the weir and use this variable in the Francis weir formula. Further details on this approach can be found in (Hoffmann et al., 2020).

\subsubsection{Activation of equilibrium}

Our formulation for thermodynamic equilibrium and energy balances contains two different temperatures, one denoting the temperature of phase equilibrium, the other the actual temperature on a tray. This separation of temperatures was already suggested in prior work, e.g., by Forner et al. (2008). It allows for the decoupling of energy balance and phase equilibrium. However, Forner et al. (2008) used an if-else switch in their model. Here, the smooth formulation via a sigmoidal $\psi_{t}$ is used, which switches to 1 as soon as the tray temperature reaches the boiling point at the given composition.

$$
\psi_{t}=0.5+0.5 \cdot \frac{T_{t}-T_{t}^{V L}-(10)^{-4}}{\sqrt{\left(T_{t}-T_{t}^{V L}-(10)^{-4}\right)^{2}+(10)^{-10}}} .
$$

Thus, the sigmoidal is zero for temperatures below the boiling point and one

otherwise. The small shift of $10^{-4}$ is used to avoid continuous switching of the sigmoidal due to numerical noise. If this value is chosen to be larger, the violation of the summation relation in the vapor phase gets larger as well. The boiling temperature can always be determined by the boiling point condition:

$$
P_{t}=\sum_{c=1}^{N C} x_{t, c}^{L} \cdot P_{t, c}^{V}\left(T_{t}^{V L}\right)
$$

The sigmoidal automatically provides for the necessary switching in the relevant constraint as soon as the boiling point is reached. Below the boiling point, the vapor flow is set to zero. At the boiling point, the equality of the 
temperatures is enforced:

$$
\left(T_{t}^{V L}-T_{t}\right) \cdot \psi_{t}+\left(1-\psi_{t}\right) \cdot F_{t}^{V}=0
$$

The sigmoidal also activates the vapor holdup:

$$
\psi_{t} \cdot H U_{t}^{V}=H U_{t}^{V, \text { actual }}
$$

Before this activation, the vapor holdup is calculated from the liquid and tray volume but is not considered for the internal energy or the component holdups as inert gases are neglected.

\subsubsection{Heat loss and geometric constraints}

Heat loss $Q_{t}^{\text {loss }}$ is considered via the heat transfer coefficient $\alpha_{t}$, which can be set to an appropriate value:

$$
Q_{t}^{\text {loss }}=\alpha_{t} \cdot A^{\text {tray }} \cdot\left(T_{t}-T_{\text {ref }}\right)
$$

In addition, the heat loss depends on the lateral area of the tray $A^{\text {tray }}$ and the temperature difference between tray and a reference point, usually ambient temperature.

The geometric parameters of the trays are functions of the tray's material density $\rho_{\text {tray }}$ and its thickness $h_{\text {tray }}$, the column diameter $D_{\text {column }}$, wall thickness of the column $\lambda_{\text {wall }}$, and tray spacing $H$. The geometric parameters are illustrated in Figure 4.

$$
\begin{gathered}
m^{\text {tray }}=\rho^{\text {tray }} \cdot\left(A_{\text {active }} \cdot h^{\text {tray }}+\frac{\pi}{4} \cdot\left(\left(D_{\text {column }}+2 \cdot \lambda_{\text {wall }}\right)^{2}-\left(D_{\text {column }}\right)^{2}\right) \cdot H\right), \\
A_{\text {column }}=\frac{\pi}{4} \cdot\left(D_{\text {column }}\right)^{2}
\end{gathered}
$$




$$
\begin{gathered}
A^{\mathrm{dc}}=\frac{\left(D_{\text {column }}\right)^{2}}{8} \cdot\left(\frac{\phi \cdot \pi}{180}-\sin \left(\frac{\phi \cdot \pi}{180}\right)\right), \\
A_{\text {active }}=A_{\text {column }}-2 \cdot A^{\mathrm{dc}}, \\
V^{\text {tray }}=A_{\text {active }} \cdot H, \\
A^{\text {tray }}=\pi \cdot\left(D_{\text {column }}+2 \cdot \lambda_{\text {wall }}\right) \cdot H, \\
X_{\text {weir }} \cdot D_{\text {column }}=L_{\text {weir }}, \\
\sin \left(\frac{\phi \cdot \pi}{180 \cdot 2}\right)=X_{\text {weir }} .
\end{gathered}
$$

\subsubsection{Murphree efficiencies and entrainment}

Up to now, the vapor mole fractions on a tray are not connected to thermodynamics. Therefore, Murphree efficiences $E_{t}$ are applied as introduced in Section 2:

$$
x_{t, c}^{V}=\left(E_{t} \cdot\left(x_{t, c}^{V \text {,equi }}-x_{t+1, c}^{V}\right)+x_{t+1, c}^{V}\right) \cdot \psi_{t}
$$

However, they are slightly changed by multiplying the right side with the sigmoidal $\psi_{t}$ of tray $t$. Thus, the vapor mole fraction remains zero until the temperature reached the boiling point.

Equation (5) is also modified by adding $10^{-3}$ on both sides to $\lambda_{t}$ as the equation's derivative is otherwise undefined when $\lambda_{t}$ is zero:

$$
E_{t} \cdot\left(\lambda_{t}+(10)^{-3}-1\right)=\left(\left(\lambda_{t}+(10)^{-3}\right)^{E_{\text {column }}}-1\right)
$$


The equations for $m_{t}$ and $\alpha_{t}^{\text {equi }}$ remain valid in all states but the stream ratio $S R_{t}$ is also modified to avoid division by zero whenever the liquid flow disappears:

$$
\begin{gathered}
\lambda_{t}=m_{t} \cdot S R_{t}, \\
S R_{t} \cdot\left(F_{t-1}^{L}+(10)^{-3}\right)=F_{t+1}^{V} .
\end{gathered}
$$

A similar modification is also applied to the entrainment equation for the case when there is no vapor flow and the superficial vapor velocity is zero:

$\left(e_{t}\right) \cdot\left(\left(H-2.5 \cdot h_{c l, t}\right) \cdot 39.37\right)^{b} \cdot \sum_{c=1}^{N C} x_{t, c}^{L} \cdot \sigma_{t, c} \cdot(10)^{3}=a \cdot\left(\left(w_{t}^{V}+(10)^{-3}\right) \cdot 3.28\right)^{b}$

Therein, $e_{t}$ is the ratio of the entrained mass flow to the vapor flow from tray $t$.

\subsection{Downcomer}

The following assumptions are made for the downcomer:

- The liquid in the downcomer is ideally mixed;

- The energy balance is neglected, i.e., the liquid enthalpy is equal to the enthalpy on the preceding tray;

- The molar volume of the liquid is constant;

- Vapor may not go through the downcomer, even when there is no liquid to seal it. 
Mole balance and liquid level: The mole balance for the downcomer contains the liquid inlet from the weir above, the outlet to the next tray, and a potential backflow. This backflow appears, for example, when a tray above the feed tray starts filling up:

$$
\frac{\mathrm{d} H U_{d c, c}}{\mathrm{dt}}=F_{\text {weir }, t=d c}^{L} \cdot x_{t=d c, c}^{L}-F_{d c}^{L, \text { actual }} \cdot x_{d c, c}^{L}+F_{t=d c+1}^{L, \text { back,actual }} \cdot x_{t=d c+1, c}^{L}
$$

The holdup of component $c$ in the downcomer $H U_{d c, c}$ changes due to liquid entering over the weir from the tray above $F_{\text {weir,t=dc }}^{L}$, liquid flowing out of the downcomer $F_{d c}^{L \text {,actual }}$, and liquid flowing back into the downcomer $F_{t=d c+1}^{L, \text { back,actual }}$. The liquid height in the downcomer $h_{\mathrm{cl}, d c}$ is determined by a momentum balance. The left-hand side is given by the sum of the pressure drop over the tray $\Delta P_{t=d c+1}^{\text {tray }}$, the hydrostatic pressure on the current tray (represented by the liquid density and height on this tray), and the head loss beneath the downcomer apron (represented by the liquid density and $h_{d c}^{\text {flow }}$ ) (Green and Perry, 2007, p. 14-39):

$$
\Delta P_{t=d c+1}^{\text {tray }} \cdot 10^{5}+\rho_{t=d c+1}^{L} \cdot g \cdot h_{\mathrm{cl}, t=d c+1}+\rho_{t=d c}^{L} \cdot g \cdot h_{d c}^{\text {flow }}=\rho_{t=d c}^{L} \cdot g \cdot h_{\mathrm{cl}, d c} .
$$

As the liquid heights on the trays and the downcomers follow from the mole balances, Equation (47) yields the head loss $h_{d c}^{\text {flow }}$, which determines the liquid outlet.

Streams: The modeling approach for the downcomer is as follows: If there is no vapor flow upwards, the levels in both tray and downcomer are supposed to be equal. As long as there is no vapor flow from the tray $\left(\psi_{t}=0\right)$, the liquid flow to and from the tray, $F_{d c}^{L}$ and $F_{t=d c+1}^{L, \text { back }}$, are computed by the level difference in both control volumes using a proportionality constant $K^{\mathrm{dc}}$. If 
there is a vapor flow $\left(\psi_{t}=1\right)$, the liquid outlet from the downcomer to the next tray is calculated by the second term in Equation (9):

$$
\begin{aligned}
F_{d c}^{L}= & K^{\mathrm{dc}} \cdot\left(h_{\mathrm{cl}, d c}-h_{\mathrm{cl}, t=d c+1}\right) \cdot\left(1-\psi_{t=d c+1}\right) \\
& +\frac{1}{v_{d c}^{L}} \cdot \frac{\overbrace{X_{\text {weir }} \cdot D_{\text {column }} \cdot Y_{\text {weir }} \cdot h_{\text {weir }}}^{\text {Area under downcomer apron }}}{\sqrt{0.1652}} \cdot \sqrt{h_{d c}^{\text {flow,actual }}} \cdot \psi_{t=d c+1},
\end{aligned}
$$

The same approach is taken for the back flow from tray to downcomer:

$$
F_{t=d c+1}^{L, \mathrm{back}}=K^{\mathrm{dc}} \cdot\left(h_{\mathrm{cl}, t=d c+1}-h_{\mathrm{cl}, d c}\right)
$$

Similar to the height above the weir in Equation (27), Equation (47) also may lead to a negative $h_{d c}^{\text {flow }}$, e.g., when the tray is still empty. Therefore, another max operator is applied. This variable is used within Equation (48);

$$
h_{d c}^{\text {flow,actual }}=\max \left(h_{d c}^{\text {flow }}, 0\right) .
$$

Because downcomer and tray have different composition, only one direction for either stream is allowed:

$$
\begin{gathered}
F_{d c}^{L, \text { actual }}=\max \left(F_{d c}^{L}, 0\right), \\
F_{t=d c+1}^{L, \text { back,actual }}=\max \left(F_{t=d c+1}^{L, \text { back }}, 0\right) .
\end{gathered}
$$

\subsection{Reboiler}

The following assumptions are made for the reboiler:

- Murphree efficiencies are assumed to be one;

- The molar volume of the liquid is constant; 
- The liquid in the reboiler is ideally mixed;

- There is no entrainment in the reboiler due to its large volume.

The reboiler's equations are to a large part equal to those on the trays. The reboiler also contains dynamic mole and energy balances, the phase equilibrium, and the pressure drop calculation. The energy balance considers both the heat-up of the reboiler material and the heat loss. Equilibrium is activated as soon as the boiling point is reached. In analogy to the reflux drum, the temperature controller for the reboiler,

$$
Q_{\text {reboiler }}=\left(Q_{\text {reboiler }}^{\mathrm{SP}}-K_{\text {reboiler }} \cdot\left(T_{t=\text { tCtrlReb }}-T_{t=\mathrm{tCtrlReb}}^{\mathrm{SP}}\right) \cdot \Upsilon\right) \cdot \gamma_{\text {reboiler }},
$$

is coupled to a sigmoidal $\gamma_{\text {reboiler }}$, which switches to one as soon as a certain liquid level in the reboiler is attained:

$$
\gamma_{\text {reboiler }}=0.5+0.5 \cdot \frac{h_{c l, t=N T+1}-h_{\text {reboiler }}^{\mathrm{SP}}}{\sqrt{\left(h_{\mathrm{cl}, t=N T+1}-h_{\mathrm{reboiler}}^{\mathrm{SP}}\right)^{2}+(10)^{-5}}} .
$$

Again, $\Upsilon$ activates or deactivates the control.

\subsection{Model structure and implementation}

The model is implemented in MOSAICmodeling, a web-based modeling, simulation, and optimization environment (Merchan et al., 2015, Esche et al., 2017). A modular setup for the model components is chosen, which is illustrated in Figure 5. Thus, specific models elements can be exchanged quickly and single effects, such as heat loss, thermodynamic efficiencies, or entrainment, can be turned off to investigate their impact on both results and numerical stability during the integration. Of course, the model can be extended in the future, which is indicated by the dots. 


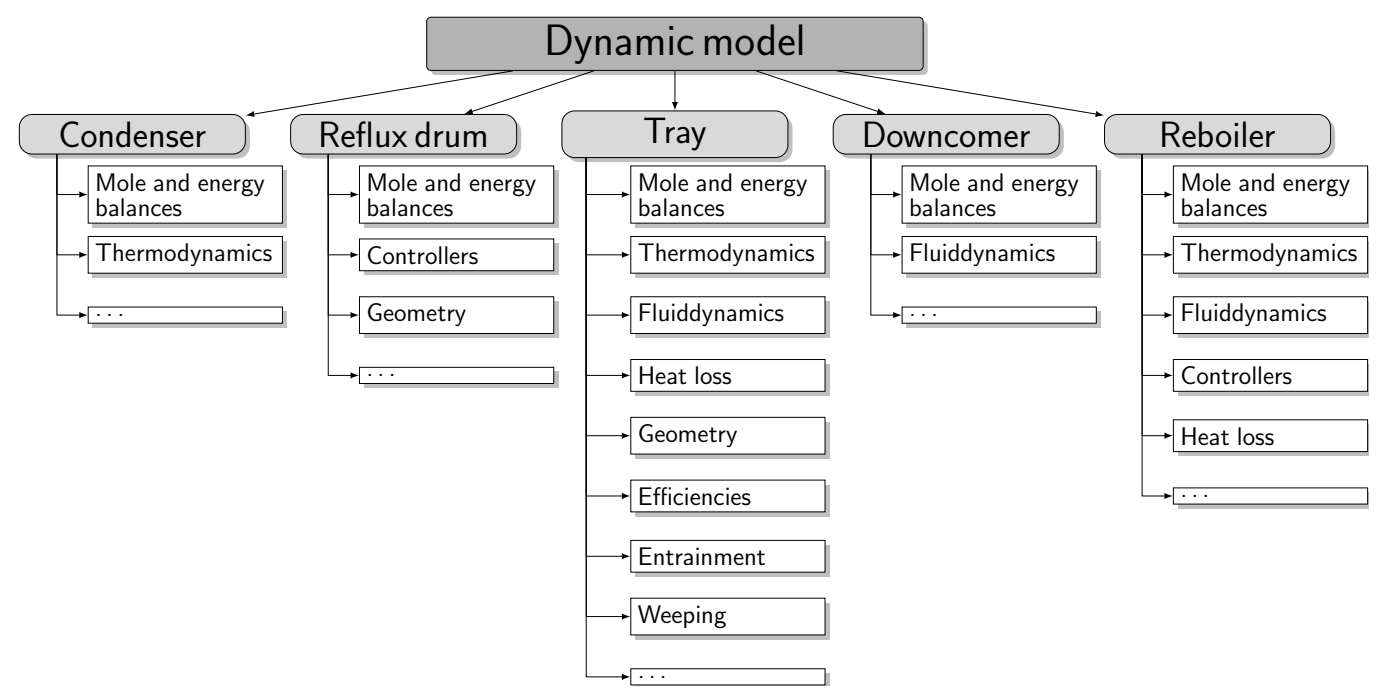

Figure 5: Model structure within MOSAICmodeling.

Using MOSAICmodeling's code generator for various programming languages and modeling environments, the dynamic system is exported to the gPROMS model builder version 5.1.1 (Process Systems Enterprise, 19972018).

\section{Simulation studies}

In this section, we report results obtained with the presented model for a case study, a distillation of a binary mixture of benzene (1) and toluene (2). However, the model could easily be extended to multicomponent distillation. The only necessary additions to the presented model would be the aforementioned Murphree efficiences for multicomponent systems Chan and Fair, 1984b). Optionally, activity models or equations of state to accurately predict the thermodynamic properties and the possibility of side streams for multicomponent separation could be considered . 
Table 2: Solver settings in gPROMS model builder. All other settings are set to default.

\begin{tabular}{cc}
\hline Setting & Value \\
\hline Solver name & DAEBDF \\
MaxCorrectorIterations & 50 \\
MaxSuccessiveCorrectorFailures & 100 \\
RelativeTolerance & $1.0 \mathrm{E}-8$ \\
Use steady-state initial conditions & no \\
\hline
\end{tabular}

First, we compare results with excluded phenomena, such as Murphree efficiencies, entrainment, and downcomers. Then, the system is solved for a larger numbers of trays to demonstrate its scalability. Throughout this contribution, the solver options given in Table 2 are used.

Specifications: All references for the properties of benzene and toluene are given in Table 3 , the design decisions made for the following simulation studies are given in Table 4 , Table 6 contains the initial conditions for holdups and internal energies.

\subsection{Model verification with Aspen Plusß}

Before analyzing the results of the dynamic simulations, we ensure that the model cannot only be solved but yields the correct steady-state. For this purpose, an Aspen Plus@ model with the same design specifications as in Table 4 is set up. Both models have 10 trays and the feed is added on the fifth tray.

The obtained temperature profile from Aspen Plus@ was used to specify the setpoints for the controllers in our dynamic model (Table 7). The most 
Table 3: Component data.

\begin{tabular}{cc|c}
\hline Property & \multicolumn{1}{c}{ Reference } \\
\hline Enthalpy of formation & Green and Perry & 2007) \\
Enthalpy of vaporization & Green and Perry & 2007) \\
Surface tension & (VDI, 2013 & \\
Vapor pressure & Green and Perry & 2007) \\
Liquid heat capacity & Green and Perry & 2007) \\
Ideal gas heat capacity & Green and Perry & 2007) \\
Molecular weight & Green and Perry & 2007) \\
\hline
\end{tabular}

sensitive trays with respect to the controls were determined with a sensitivity analysis. Figure 6 and Figure 7 show a good agreement between Aspen Plus $\AA$ and the proposed model for both the temperature and the concentration profile when plotted against the column trays. In addition, Table 5 compares the calculated heat duties and product streams and shows a very good match. The minor differences are due to small control deviations as we use proportional controllers. Our model is thus capable of accurately

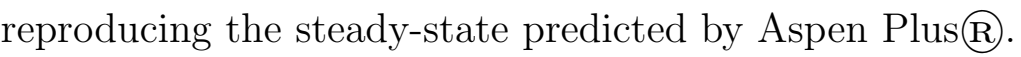

\subsection{Dynamic simulations of startup, continuous operation, and shutdown}

We now demonstrate the capabilities of the developed dynamic column model by simulating all four phases stated in Section 2. First, the results for

\footnotetext{
${ }^{1}$ The hyperbolic expression from the reference was linearized and new parameters were regressed in the temperature range from 298 to $400 \mathrm{~K}$.
} 
Table 4: Design specifications.

\begin{tabular}{|c|c|c|c|c|c|}
\hline Variable & Value & Unit & Variable & Value & Unit \\
\hline \multicolumn{6}{|c|}{ Condenser and reflux drum } \\
\hline$\Delta T_{\mathrm{CON}}$ & 10 & $\mathrm{~K}$ & $L_{\mathrm{RD}}$ & 2.65 & $\mathrm{~m}$ \\
\hline$P_{\mathrm{CON}}$ & 1.013 & bar & $V A_{\mathrm{RD}}$ & -2.74 & - \\
\hline$D_{\mathrm{RD}}$ & 0.884 & $\mathrm{~m}$ & $V B_{\mathrm{RD}}$ & 3.66 & $\mathrm{~m}$ \\
\hline$F_{t=0}^{L, \mathrm{SP}}$ & 14 & $\mathrm{mols}^{-1}$ & $V C_{\mathrm{RD}}$ & 0.76 & $\mathrm{~m}^{2}$ \\
\hline$F_{\text {dist }}^{\mathrm{SP}}$ & 10 & $\operatorname{mols}^{-1}$ & $v_{R D}^{L}$ & $9.7 \cdot 10^{-5}$ & $\mathrm{~m}^{3} \mathrm{~mol}^{-1}$ \\
\hline \multicolumn{6}{|l|}{ Tray } \\
\hline$\alpha_{t}$ & 0.025 & $\mathrm{~kW} \mathrm{~m}^{-2} \mathrm{~K}^{-1}$ & $L_{\text {tube }}$ & 10 & $\mathrm{~m}$ \\
\hline$\delta_{\text {tube }}$ & 0.3 & $\mathrm{~m}$ & $T^{\text {feed }}$ & 298.15 & $\mathrm{~K}$ \\
\hline$\lambda_{\text {wall }}$ & 0.005 & $\mathrm{~m}$ & $X_{\text {weir }}$ & 0.7 & - \\
\hline$\nu$ & $9.0 \cdot 10^{-6}$ & $\mathrm{~m}^{2} \mathrm{~s}^{-1}$ & $a$ & 16.06 & - \\
\hline$\rho^{\text {tray }}$ & 8050 & $\mathrm{~kg} \mathrm{~m}^{-3}$ & $b$ & 3.2 & - \\
\hline$\xi$ & 300 & - & $c_{\text {tray }}$ & 0.5 & $\mathrm{~kJ} \mathrm{~kg}^{-1}$ \\
\hline$\xi_{\text {corner }}$ & 1.2 & - & $h_{\text {tray }}$ & 0.005 & $\mathrm{~m}$ \\
\hline$D_{\text {column }}$ & 1 & $\mathrm{~m}$ & $h_{\text {weir }}$ & 0.04 & $\mathrm{~m}$ \\
\hline$E_{\text {column }}$ & 0.8 & - & $v_{t}^{L}$ & $9.7 \cdot 10^{-5}$ & $\mathrm{~m}^{3} \mathrm{~mol}^{-1}$ \\
\hline$F_{t}^{\text {feed }}$ & 20 & $\mathrm{mols}^{-1}$ & $x_{t, c}^{\mathrm{feed}}$ & 0.5 & $\mathrm{~mol} \mathrm{~mol}^{-1}$ \\
\hline$H$ & 0.5 & $\mathrm{~m}$ & & & \\
\hline \multicolumn{6}{|c|}{ Downcomer } \\
\hline$Y_{\text {weir }}$ & 0.8 & - & $v_{d c}^{L}$ & $9.7 \cdot 10^{-5}$ & $\mathrm{~m}^{3} \mathrm{~mol}^{-1}$ \\
\hline \multicolumn{6}{|c|}{ Reboiler } \\
\hline$\alpha_{\text {reboiler }}$ & 0.025 & $\mathrm{~kW} \mathrm{~m}^{-2} \mathrm{~K}^{-1}$ & $c_{\text {reboiler }}$ & 0.5 & $\mathrm{~kJ} \mathrm{~kg}^{-1}$ \\
\hline$H_{\text {reboiler }}$ & 1 & $\mathrm{~m}$ & $h_{\text {reboiler }}$ & 0.5 & $\mathrm{~m}$ \\
\hline$Q_{\text {reboiler }}^{\mathrm{SP}}$ & 1000 & $\mathrm{~kW}_{30}$ & $v_{t=N T+1}^{L}$ & $9.7 \cdot 10^{-5}$ & $\mathrm{~m}^{3} \mathrm{~mol}^{-1}$ \\
\hline
\end{tabular}




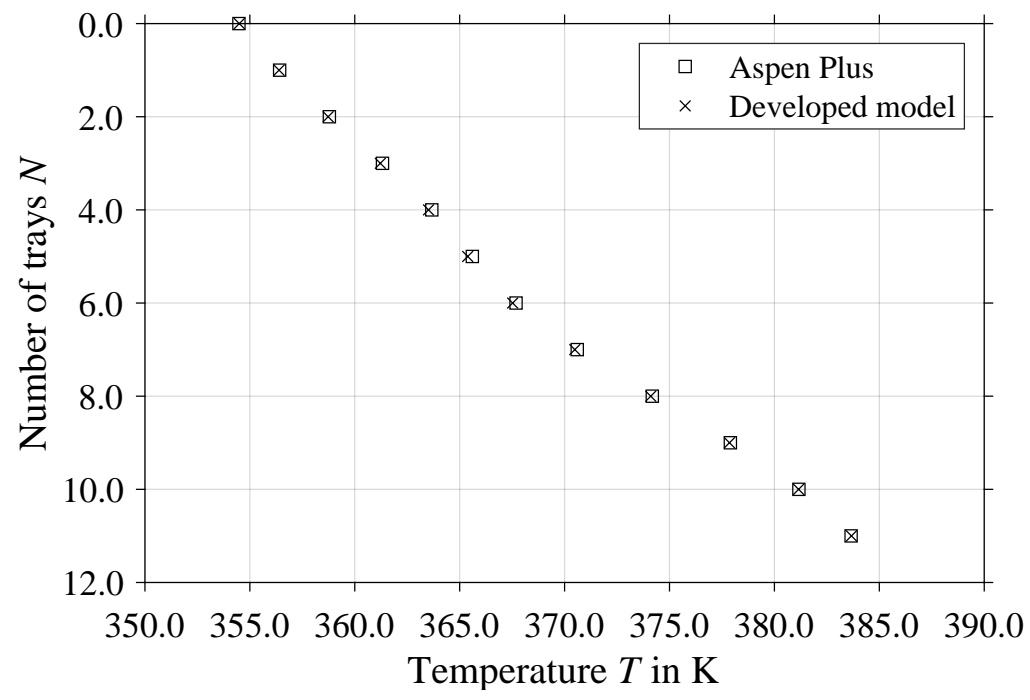

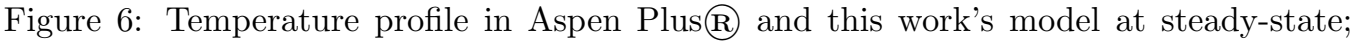
without Murphree efficiencies, entrainment, and weeping.

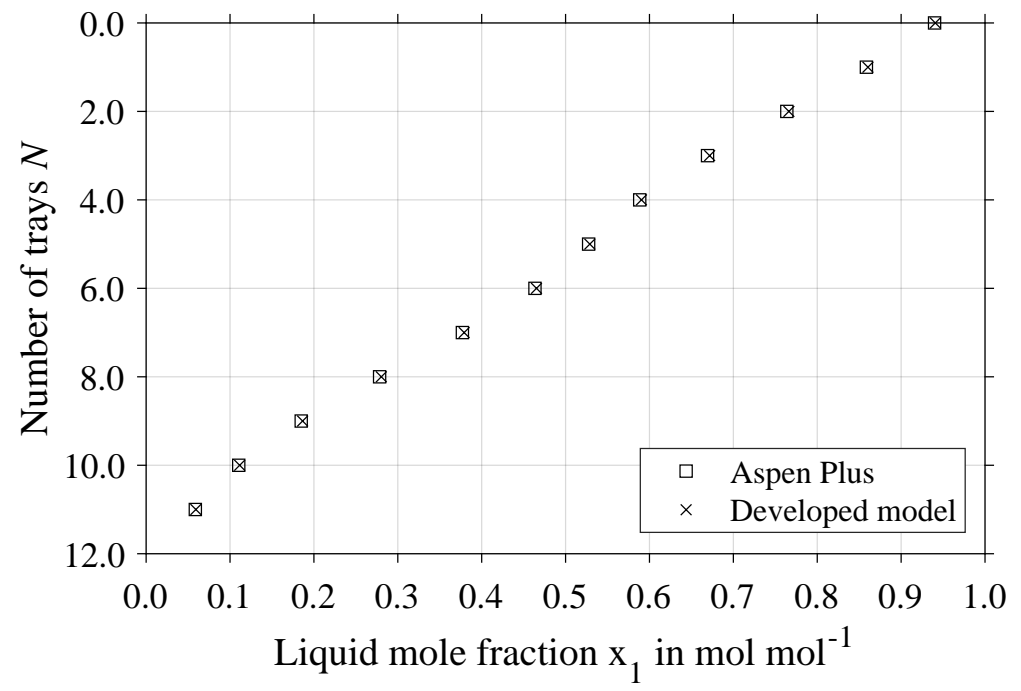

Figure 7: Liquid concentration profile in Aspen Plus@ and this work's model at steadystate; without Murphree efficiencies, entrainment, and weeping. 
Table 5: Comparison of heat duties and product flows between this work's model and Aspen Plus@.

\begin{tabular}{cccc}
\hline Variable & \multicolumn{2}{c}{ Value } & Unit \\
& This work & Aspen Plus $\mathrm{R}$ & \\
\hline$Q_{\mathrm{CON}}$ & -783 & -786 & $\mathrm{~kW}$ \\
$Q_{\text {reboiler }}$ & 999 & 1001 & $\mathrm{~kW}$ \\
$F^{\text {dist }}$ & 10.02 & 10 & $\mathrm{~mol} \mathrm{~s}^{-1}$ \\
$F_{t=N T+1}^{L}$ & 9.98 & 10 & $\mathrm{~mol} \mathrm{~s}^{-1}$ \\
\hline
\end{tabular}

the 10 tray column are compared for different included phenomena. Then, the model's scalability with a larger number of trays and different heat-up ratios is presented.

\subsubsection{Comparison with different phenomena}

Throughout this section, we use the initial conditions for holdups and internal energies in reflux drum, trays, downcomers, and reboiler as given in Table 6. Essentially, all trays, the reflux drum, and the reboiler are empty and the temperature on all trays is $298.15 \mathrm{~K}$. The controller setpoints for the temperatures given in Table 7 for the column model for this base case with 10 trays were obtained by solving the steady-state model in Aspen Plus@R. The set point for the reflux drum of $0.25 \mathrm{~m}$ was chosen arbitrarily.

In the following, we compare simulation results for five versions of the proposed model, in which the phenomena described in Table 8 are either included or neglected. In the case of a downcomer at steady-state, the equations presented in Section 3.4 are replaced by a steady-state component balance and 
Table 6: Initial conditions. The initial condition for the internal energy is given by the initial holdup, the assumed initial temperature of $298.15 \mathrm{~K}$, and the respective initial product of pressure and volume.

\begin{tabular}{|c|c|c|c|c|c|}
\hline Variable & Value & Unit & Variable & Value & Unit \\
\hline$H U_{\mathrm{RD}, c} ; H U_{t, c}$ & 0.05 & mol & $U_{t}$ & $-29.73^{2}$ & $\mathrm{~kJ} \mathrm{~mol}^{-1}$ \\
\hline$H U_{d c, c}$ & 0.005 & mol & & & \\
\hline$H U_{t=N T+1, c}$ & 0.05 & mol & $U_{t=N T+1}$ & -76.48 & $\mathrm{~kJ} \mathrm{~mol}^{-1}$ \\
\hline
\end{tabular}

Table 7: Controller and tuning parameters and setpoints for base case with 10 trays.

\begin{tabular}{ccccccc}
\hline Variable & Value & Unit & & Variable & Value & Unit \\
\cline { 6 - 7 }$\epsilon$ & $10^{-6}$ & various & & $L_{\mathrm{RD}}^{L, \mathrm{SP}}$ & 0.25 & $\mathrm{~m}$ \\
$K_{t=0}$ & 1 & $\mathrm{~mol} \mathrm{~s}^{-1} \mathrm{~K}^{-1}$ & & $L_{\mathrm{RD}}^{\mathrm{min}}$ & 0.05 & $\mathrm{~m}$ \\
$K^{\mathrm{dc}}$ & 1000 & $\mathrm{~mol} \mathrm{~s}^{-1} \mathrm{~m}^{-1}$ & & $h_{\mathrm{reboiler}}^{\mathrm{SP}}$ & 0.4 & $\mathrm{~m}$ \\
$K^{\text {dist }}$ & 10 & $\mathrm{~mol} \mathrm{~s}^{-1} \mathrm{~m}^{-1}$ & & $T_{t=3}^{\mathrm{SP}}$ & 361 & $\mathrm{~K}$ \\
$K_{\text {reboiler }}$ & 5 & $\mathrm{~mol} \mathrm{~s}^{-1} \mathrm{~K}^{-1}$ & & $T_{t=8}^{\mathrm{SP}}$ & 374 & $\mathrm{~K}$ \\
\hline
\end{tabular}

Table 8: Phenomena in different model versions.

\begin{tabular}{ccccc}
\hline Model version & Weeping & Entrainment & Murphree efficiencies & Downcomer \\
\hline 1 & yes & yes & yes & dynamic \\
2 & no & yes & yes & dynamic \\
3 & no & no & yes & dynamic \\
4 & no & no & no & dynamic \\
5 & yes & yes & yes & steady-state \\
\hline
\end{tabular}


an equation setting the sum of the mole fractions in the downcomer to one. The different model versions are solved for the following dynamic scenario:

1. The feed enters the column until the reboiler is filled to $0.4 \mathrm{~m}$, controllers are deactivated or set to infinite reflux by setting $\Upsilon$ to 0

2. The reboiler duty is linearly increased over half an hour until it reaches its steady-state value

3. The temperature controller for the reboiler duty is activated by setting $\Upsilon$ to 1

4. The system runs for $2 \mathrm{~h}$

5. feed, reboiler duty, and reflux are linearly decreased to 0 over half an hour, $v$ is set to 0 again

6. The system operates with no feed for another half hour

The results for the dynamic temperature profile and the profile of the liquid mole fraction of the light component benzene are shown in Figure 8 and Figure 9. For clarity, only the first tray and the reboiler temperature are shown as well as the liquid mole fractions of distillate and bottom product.

The results for all five model versions are very similar at first glance. The bottom temperature increases until the boiling point of the mixture in the reboiler is reached. Here, the temperature increases rather slowly as we still have a large amount of the light component in the reboiler. As soon as the controller is activated (ca. $0.55 \mathrm{~h}$ ), the reboiler duty is further increased to remove the light component sufficiently from the reboiler and the temperature in the reboiler increases notably again. The temperature on the first tray increases as soon as the vapor reaches the top of the column. A steady-state is achieved between $1 \mathrm{~h}$ and $1.5 \mathrm{~h}$. At approximately $2.5 \mathrm{~h}$, 


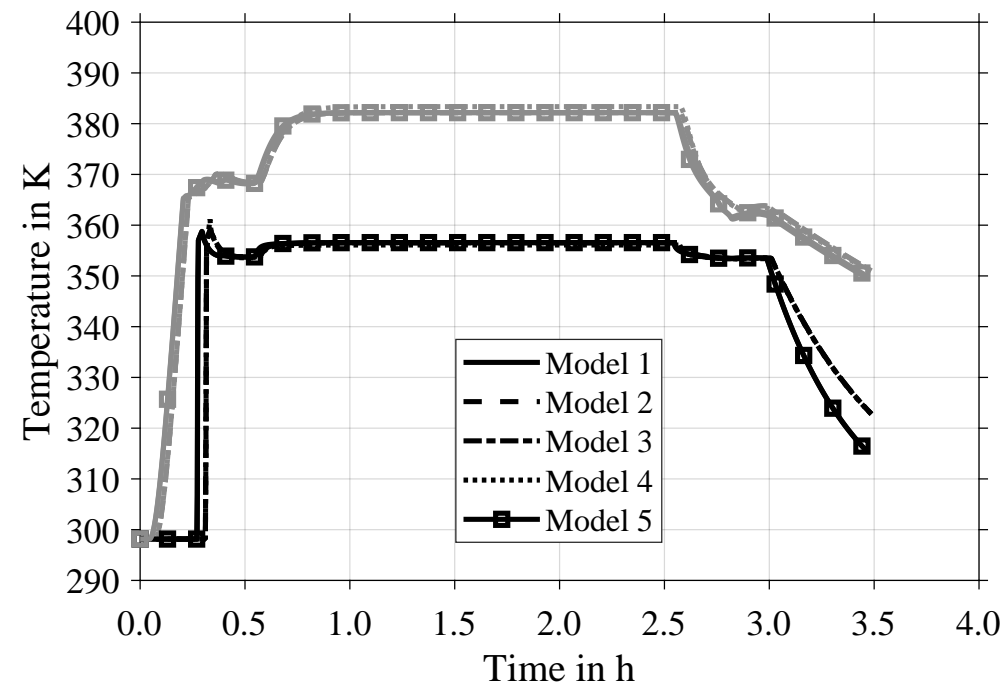

Figure 8: Temperature profiles from startup to shutdown for 10 trays; black: tray $t=1$, gray: reboiler.

the reboiler duty and the feed are turned off, hence the temperature drops and the liquid mole fraction of the light component in the reboiler increases. The mole fraction at the top also increases due to infinite reflux. The model is thus able to simulate all four phases discussed in Section 2. Note that at nominal operation is not notably affected by entrainment or weeping. However, the operation point changes in case Murphree efficiencies are not considered (dotted lines).

To study the behavior in the transient areas, Figure 10 to Figure 12 show only the first hour of operation. Figure 10 displays the steady temperature increase of the reboiler until the booiling point is reached at $0.3 \mathrm{~h}$. In addition, the models considering weeping predict a faster startup during the first $0.2 \mathrm{~h}$ because the trays between feed tray and reboiler are not filled up but the liquid weeps through the holes. Afterward, the weeping slows down the 


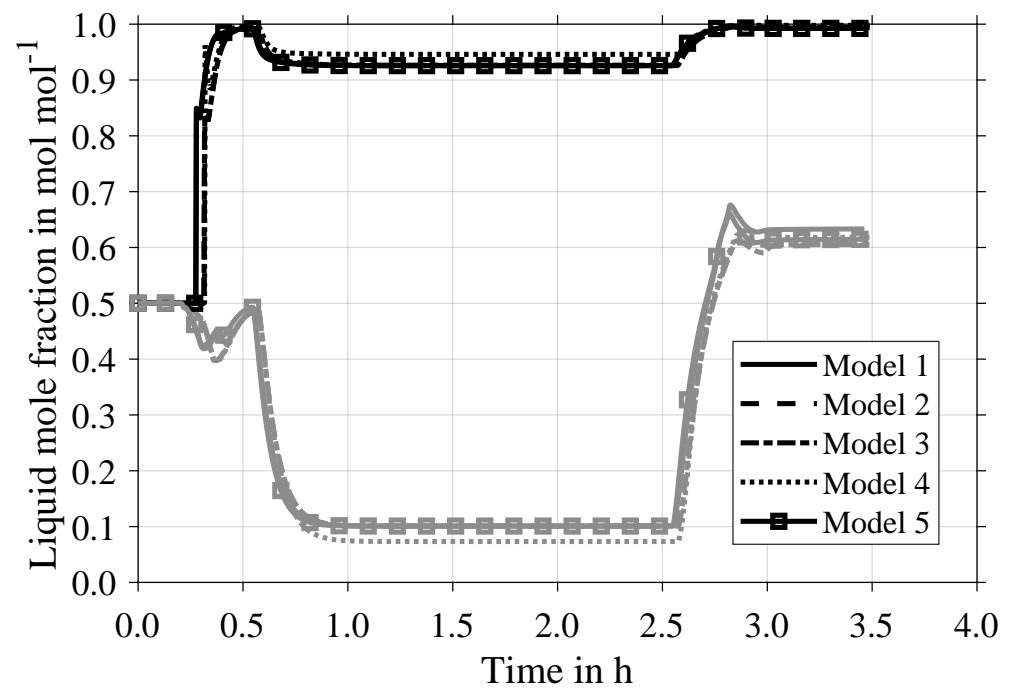

Figure 9: Profile of liquid mole fraction from startup to shutdown for 10 trays; black: tray $t=0$, gray: reboiler.

purification in the reboiler due to back-mixing of the light component. For this reason, the profiles coincide. At the top of the column, the temperature also increases faster with weeping considered. The other major differences between the different model versions are: (1) Entrainment does not have a notable impact on the temperature profile because (a) the tray spacing is so large that there is no impact or (b) the gas load is too small as $\mathrm{F}$ factors range from 1.5 to $2 \mathrm{~Pa}^{0.5}$. (2) The consideration of the downcomer as a dynamic unit seems to be unnecessary based on the current modeling approach. However, this could also be attributed to the tuning of the parameter $K^{\mathrm{dc}}$, which describes the liquid outlet from the downcomer. In further investigations, it was found that the column dynamics do not depend on this parameter if weeping is considered, as the liquid then goes through the holes and not through the downcomer. In those model versions without weeping, there is a 
notable time shift during the start-up phase for varying $K^{\mathrm{dc}}$ as this parameter determines the liquid outlet of the downcomer. In this work, we choose a value so large that the levels on both tray and downcomer are equal as long as there occurs no vapor and hence accumulation of liquid in the downcomer. Note that this is only a made assumption and this approach may be revisited in future work.

Figure 11 displays the pressure profile of condenser and reboiler. The constant top pressure (Tray 0) is also shown. As soon as the boiling point is reached and the vapor starts to rise, a pressure gradient forms automatically as a consequence of the pressure-driven formulation. Note that there is no distinct difference between the different model versions. The pressure in the reboiler starts to build up, then the pressure gradient is established on the trays.

Figure 12 displays the liquid mole fractions in reboiler and condenser during start-up. It stays constant at the bottom until the liquid arrives there. However, the liquid mole fraction of the light component does not immediately drop but remains rather constant until $0.55 \mathrm{~h}$. Prior to that, light component is accumulated in the system as the level in the reboiler is often not high enough to have a liquid outlet and because evaporating light component is condensed on the trays above and re-enters the reboiler. At $0.55 \mathrm{~h}$, the controller is activated and increases the reboiler duty to evaporate the light component. The liquid mole fraction then decreases over the next half hour until it reaches its steady-state point after approximately $1 \mathrm{~h}$. This is faster in case weeping is considered because the controller is activated a little earlier. There is also no visible impact by considering entrainment. At $0.65 \mathrm{~h}$, the 


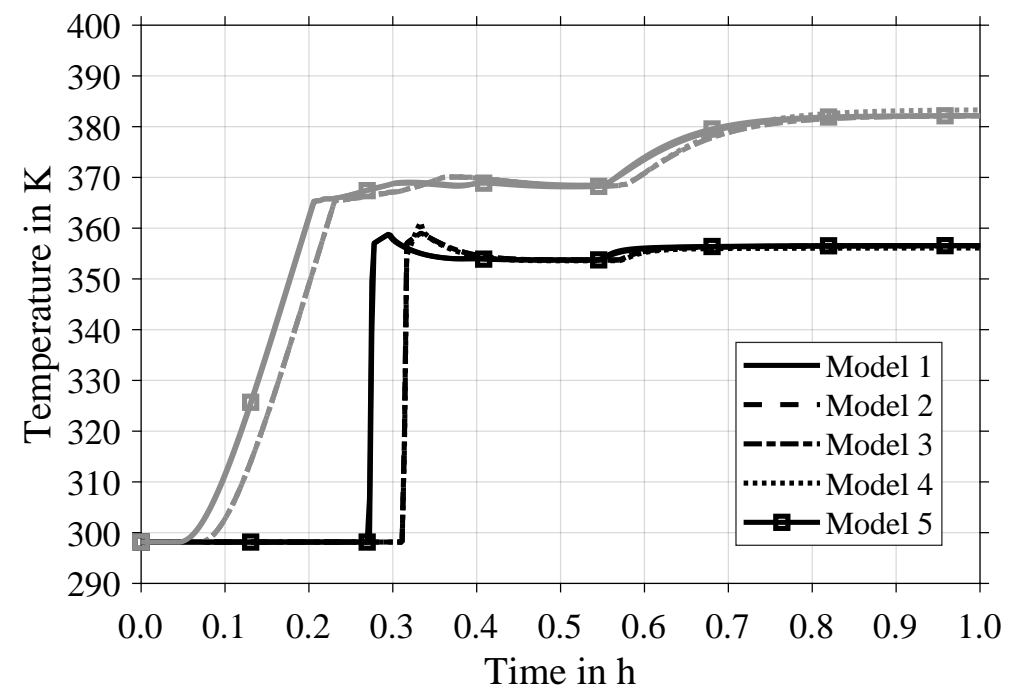

Figure 10: Temperature profiles during the first hour of operation for 10 trays; black: tray $t=1$, gray: reboiler. The differences in the profiles are mainly caused by considering/neglecting weeping in the model.

difference between those models considering Murphree efficiencies and model version 4 becomes visible. As the reflux increases, thermodynamic efficiency decreases and thus reaches another operating point than model 4 . The mole fraction in the condenser increases notably as soon as the vapor enters the condenser. Because of the large reflux to obtain the setpoint temperature, we obtain an almost pure light component at the top until the reflux decreases again and the top liquid mole fractions drops to its steady-state value. The peaks around $0.3 \mathrm{~h}$ appears when the reflux is activated. The system's response is much larger for model 4 in which thermodynamic efficiencies are always 1 . 


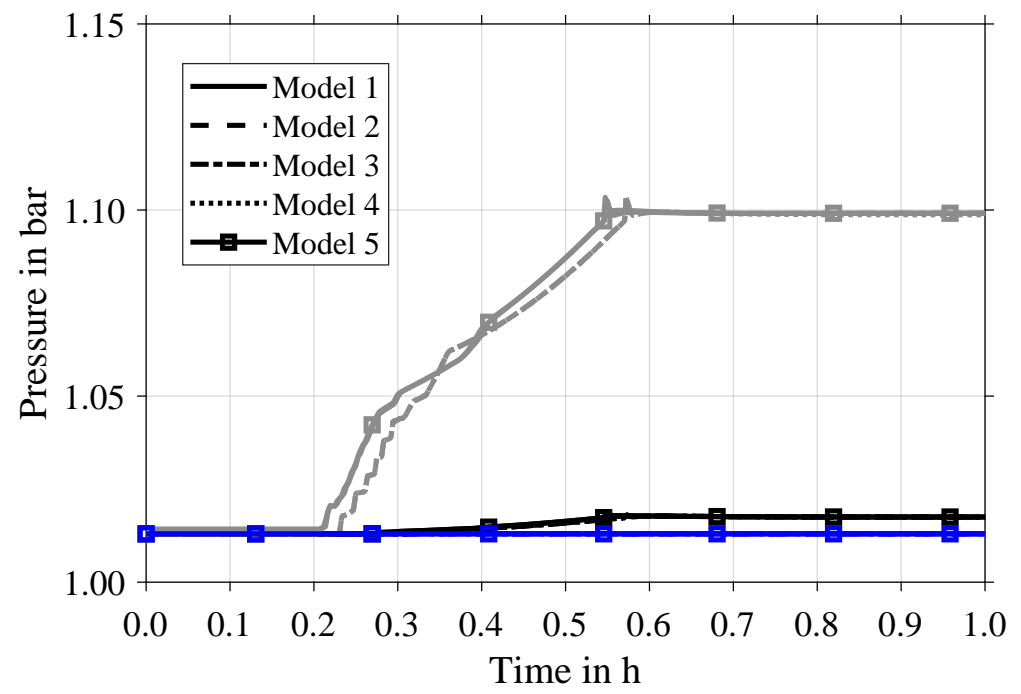

Figure 11: Pressure profile during the first hour of operation for 10 trays; blue: tray $t=0$, black: tray $t=1$, gray: reboiler.

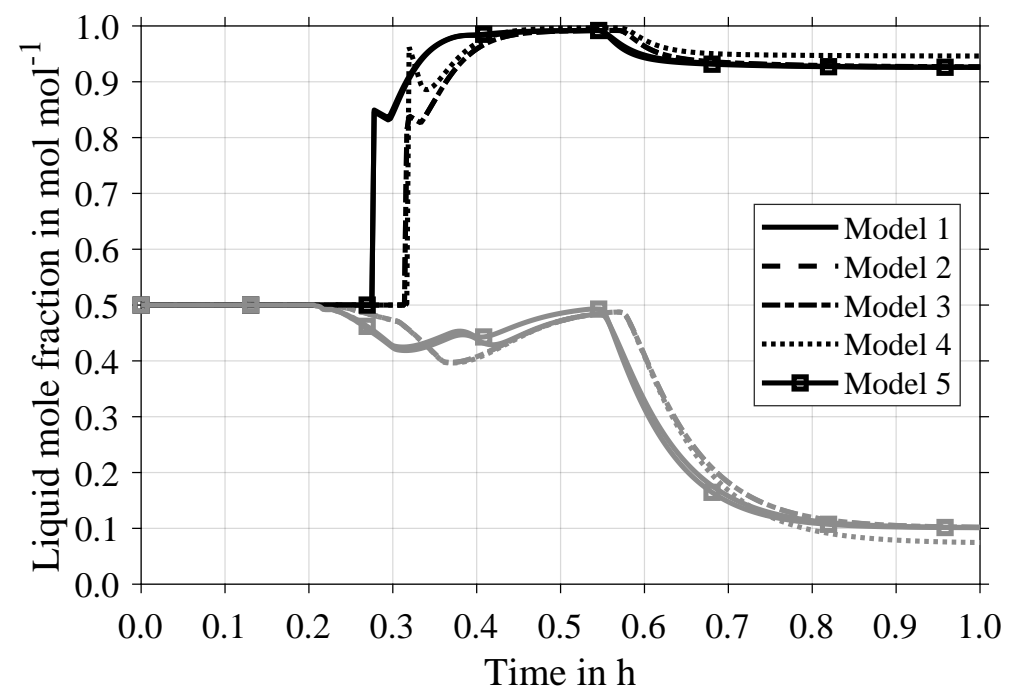

Figure 12: Profile of liquid mole fraction during the first hour of operation for 10 trays; black: tray $t=0$, gray: reboiler. 


\subsubsection{Scale-up with more trays}

The previous section showed that the model succeeds in predicting realistic start-up scenarios for a column with 10 trays and a diameter of $1 \mathrm{~m}$. However, columns vary widely in their width, i.e., diameter, and their height, i.e., number of trays. In the following, we focus on the latter case as the increase in numerical complexity is much higher here. For this reason, we show how the initialization needs to be changed to solve the model with 40 trays instead of 10, and which impact the heating ramp of the reboiler has on the process dynamics of the column. This tray number is actually much too high for this system of benzene and toluene but for the sake of demonstration, we choose such a larger tray number. In case the number of trays is increased but the geometry (diameter, etc.) remains unchanged, only the additional holdups and internal energies must be initialized. The setpoints for the controllers were again determined with a sensitivity analysis and the steady-state profile from Aspen Plus@ and are given in Table 9.

Instead of comparing the results for different included phenomena, this section shows the behavior for varying heat-up time of the reboiler and only model 1 is used for these comparisons. The base case is $0.6 \mathrm{~h}$, the same gradient as for the system with 10 trays. The other two have heat-up times of 1.2 and $1.8 \mathrm{~h}$. This results in reboiler duties presented in Figure 13. The initial peak after the heat-up time is due to the activated controller, which increases the duty to reach the setpoint temperature.

The respective temperature profiles for these three heat-up times shows Fig-

ure 14. On the one hand, the bottom temperature increases linearly while the liquid is heated up to the boiling temperature and increases more slowly 
Table 9: Controller setpoints for 40 trays.

\begin{tabular}{ccc}
\hline Variable & Value & Unit \\
\hline$L_{\mathrm{RD}}^{L, \mathrm{SP}}$ & 0.25 & $\mathrm{~m}$ \\
$T_{t=12}^{\mathrm{SP}}$ & 356 & $\mathrm{~K}$ \\
$T_{t=27}^{\mathrm{SP}}$ & 382.5 & $\mathrm{~K}$ \\
\hline
\end{tabular}

until steady-state is reached. On the other hand, the top temperature reaches its steady-state value almost instantly as the vapor is already rectified by the trays below. When the heat duty in the reboiler is reduced, the temperature in the reboiler and at the top begins to decrease. As soon as the reboiler is completely turned off, this temperature decrease is accelerated and the temperature drops due to heat loss. In case heat loss is not included in the model, the temperature on each tray remains constant at this point. By consequence, the start-up time is strongly dependent on the heat-up time.

\subsection{Implementation benefits}

Having discussed the results of the proposed model, an overview on its implementation benefits compared to a conventional and simpler model is given. This is done by assessing several operating modes and dynamic scenarios and discussing advantages and disadvantages of both approaches.

Nominal operating points with mild disturbances and small load shifts: In case a plant is expected to operate under these mild dynamic scenarios, implementing some phenomena, such as weeping or entrainment, is probably less relevant provided that the column is well designed. On the other hand, 


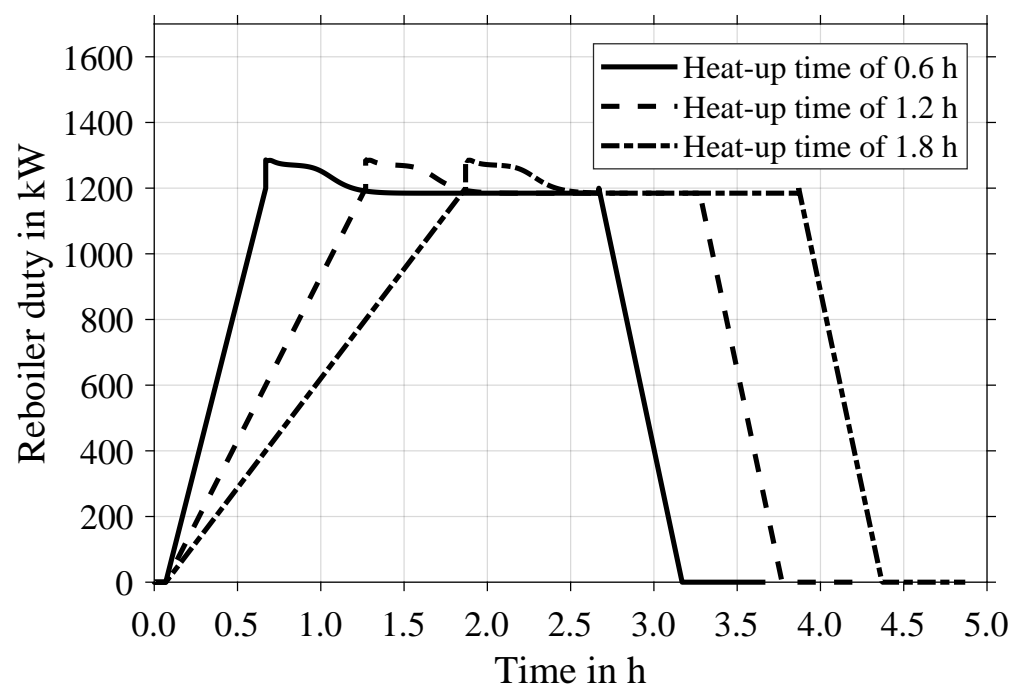

Figure 13: Reboiler duties for 40 trays and diameter of $1 \mathrm{~m}$; black: tray $t=1$, gray: reboiler.

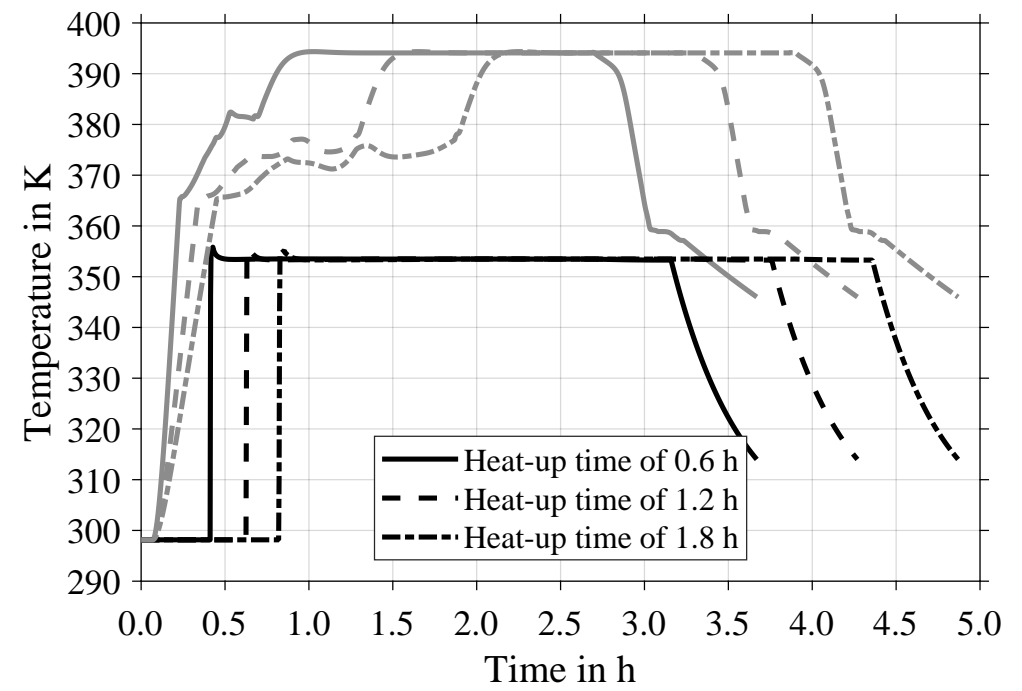

Figure 14: Temperature profiles for 40 trays and diameter of $1 \mathrm{~m}$; black: tray $t=1$, gray: reboiler. 
limitations to thermodynamic equilibrium have an impact on both steadystate and dynamic profiles and justify their implementation even for small disturbances. In addition, conventional (linear) control strategies can be easily employed under these simplified conditions. The challenge, however, remains in deciding whether a disturbance profile is mild. In such cases, it is recommended to compare simulation results with and without additional phenomena to quantify the difference between both models.

Startup and shutdown: Conventional models are unable to describe the startup and shutdown of a column. If these operating modes are analyzed in further detail, the modeling approach in this study can be highly beneficial.

Flexible operating points and/or strong disturbances: If the plant is expected to operate under these highly dynamic scenarios, our approach is deemed more suitable as it recognizes the decreasing separation efficiency due to entrainment or weeping. In the future, we expect these operating modes to appear more regularly given the increasing flexibility requirements of chemical plants. As such scenarios will favor model-based control strategies, considering the phenomena on the model scale instead of placing arbitrary restrictive bounds on decision variables could be beneficial to obtain feasible operating trajectories.

Downcomer dynamics: Our analysis revealed no notable contribution of the downcomer dynamics to the overall process dynamics in case weeping is considered. Based on these results, their implementation benefit seems to be low. This might be different for other tray types, though. 
Safety analysis and risk assessment: The conventional assumptions limit those models' use for such applications as they cannot predict flow inversion or the pressure-dependent flow through a safety valve.

\section{Conclusion and Outlook}

This contribution proposes a novel modeling approach for dynamic models of distillation columns, in which smooth relaxation of step functions and max operators are used to describe the (dis-)appearence of phases. For this purpose, a dynamic, pressure-driven model of a tray column is developed that considers weeping through the orifices of the trays, entrainment of liquid, limitations of mass transfer (represented by Murphree efficiencies), and downcomer dynamics. These phenomena are either considered or neglected in a case study for the system benzene/toluene to study their impact on the transient phases during start-up and shut-down. The steady-state is hardly influenced by weeping, entrainment, or the consideration of the downcomer. This is expected of a reasonably well designed distillation column. The consideration of Murphree efficiences, however, shift the steady-state operating point. During the transient phases, significant differences between the different profiles of up to several minutes are revealed. The different time constants will in general depend on component properties, operating specifications, as well as the geometry of the distillation column. Therefore, incorporating these phenomena in dynamic models for optimal control of continuous or batch distillation columns may be beneficial for computing accurate trajectories. This is also addressed by pointing out several operating modes for which our implementation is beneficial compared to conventional approaches. 
The presented modeling approach is able to describe the dynamic and pressure-driven behavior of the four phases of regular column operation for a industrially relevant column size of up to 40 trays without having to exchange equations or using if-else conditions. In particular, the activation of thermodynamic equilibria via a sigmoidal function should be mentioned here as it represents the key for simulating start-up and shut-down. We expect this modeling approach to be feasible not only in process simulation but also in dynamic optimization by single shooting as the presented reformulations allow for the integration of the system without using slack variables to relax discontinuous phenomena, such as (dis-)appearing thermodynamic equilibria. Whether the presented approach is robust enough for such applications shall be investigated in future work. The model could, however, also be interesting for simultaneous optimization approaches. In the past, Raghunathan and Biegler (2003) and Raghunathan et al. (2004) described the phenomena in this work using mathematical programs with equilibrium constraints. Both approaches have advantages and disadvantages and it would be highly interesting to compare them. While our model proves to yield reliable and stable results when only considering this feature, more numerical challenges arise when other phenomena are included, such as entrainment or Murphree efficiencies. In these cases, the solution becomes more dependent on the choice of control parameters or ramps of feed streams or the reboiler duty. Most numerical challenges are caused by the introduction of weeping into the model. Weeping has the property that computed values for weeping flows are quite large in case of low or zero gas loads. This may result in negative holdups on a tray for cases in which the heat-up time is too long as there is 
always a small stream leaving a tray with these smoothened max operators. With respect to scalability and the size of the equation system, it is suggested to use thermodynamic packages to externalize property function, e.g., vapor pressures or enthalpies, as these functions do not depend on the reformulations made in this work. Potentially, much computational effort can be saved at this juncture. 


\section{Acknowledgements}

The authors acknowledge the financial support by the Federal Ministry of Economic Affairs and Energy of Germany in the project ChemEFlex (project number 0350013A).

The authors would like to thank Bastian Bruns and Julia Riese from the Ruhr University Bochum for fruitful discussions during the preparation of this manuscript.

\section{References}

Albet, J., Le Lann, J.M., Joulia, X., Koehret, B., 1994. Operational policies for the start-up of batch reactive distillation columns, in: Perris, F. (Ed.), Fourth European Symposium on Computer Aided Process Engineering, ESCAPE 4: A Three-day Symposium, IChemE. pp. 64-70.

Balakrishna, S., Biegler, L.T., 1992. Targeting strategies for the synthesis and energy integration of nonisothermal reactor networks. Industrial \& Engineering Chemistry Research 31, 2152-2164. doi:10.1021/ie00009a013.

Beek, W., Muttzall, K., van Heuven, J., 1999. Transport Phenomena. John Wiley \& Sons.

Bennett, D.L., Agrawal, R., Cook, P.J., 1983. New pressure drop correlation for sieve tray distillation columns. AIChE Journal 29, 434-442. doi:10. 1002/aic.690290313.

Cameron, I., Ruiz, C., Gani, R., 1986. A generalized model for distillation 
columns-II. Computers \& Chemical Engineering 10, 199-211. doi:10. 1016/0098-1354(86)85002-5.

Chan, H., Fair, J.R., 1984a. Prediction of point efficiencies on sieve trays. 1. binary systems. Industrial \& Engineering Chemistry Process Design and Development 23, 814-819. doi:10.1021/i200027a032.

Chan, H., Fair, J.R., 1984b. Prediction of point efficiencies on sieve trays. 2. multicomponent systems. Industrial \& Engineering Chemistry Process Design and Development 23, 820-827. doi:10.1021/i200027a033.

Duran, M., 1984. A Mixed Integer Nonlinear Programming Approach for the Systematic Synthesis of Engineering Systems. Ph.D. thesis. Carnegie Mellon University.

Elgue, S., Prat, L., Cabassud, M., Lann, J.L., Cézerac, J., 2004. Dynamic models for start-up operations of batch distillation columns with experimental validation. Computers \& Chemical Engineering 28, 2735-2747. doi: $10.1016 / j$. compchemeng.2004.07.033.

Esche, E., Hoffmann, C., Illner, M., Müller, D., Fillinger, S., Tolksdorf, G., Bonart, H., Wozny, G., Repke, J.U., 2017. MOSAIC - enabling largescale equation-based flow sheet optimization. Chemie Ingenieur Technik 89, 620-635. doi:10.1002/cite. 201600114.

Flender, M., 1998. Zeitoptimale Strategien für Anfahr- und Produktwechselvorgänge an Rektifizieranlagen. Ph.D. thesis. Technische Universität Berlin. 
Flender, M., Wozny, G., Fieg, G., 1998. Time-optimal startup of a packed distillation column. IFAC Proceedings Volumes 31, 111-116. doi:10.1016/ s1474-6670(17)44915-9.

Forner, F., Brehelin, M., Rouzineau, D., Meyer, M., Repke, J.U., 2008. Startup of a reactive distillation process with a decanter. Chemical Engineering and Processing: Process Intensification 47, 1976-1985. doi:10. 1016/j.cep.2007.09.005.

Gani, R., Ruiz, C., Cameron, I., 1986. A generalized model for distillation columns-I. Computers \& Chemical Engineering 10, 181-198. doi:10. 1016/0098-1354(86)85001-3.

Gonzalez-Velasco, J.R., Gutierrez-Ortiz, M.A., Castresana-Pelayo, J.M., Gonzalez-Marcos, J.A., 1987. Improvements in batch distillation startup. Industrial \& Engineering Chemistry Research 26, 745-750. doi:10.1021/ ie00064a020.

Gopal, V., Biegler, L.T., 1999. Smoothing methods for complementarity problems in process engineering. AIChE Journal 45, 1535-1547. doi:10. 1002/aic.690450715.

Green, D.W., Perry, R.H., 2007. Perry's Chemical Engineers' Handbook, Eighth Edition. McGraw-Hill Education.

Hoffmann, C., Weigert, J., Esche, E., Repke, J.U., 2020. Towards demandside management of the chlor-alkali electrolysis: Dynamic, pressure-driven modeling and model validation of the 1,2-dichloroethane synthesis. Chemical Engineering Science 214, 115358. doi:10.1016/j.ces.2019.115358. 
Hunt, C.D., Hanson, D.N., Wilke, C.R., 1955. Capacity factors in the performance of perforated-plate columns. AIChE Journal 1, 441-451. doi:10.1002/aic.690010410.

Kender, R., Wunderlich, B., Thomas, I., Peschel, A., Rehfeldt, S., Klein, H., 2019. Pressure-driven dynamic simulation of start up and shutdown procedures of distillation columns in air separation units. Chemical Engineering Research and Design 147, 98-112. doi:10.1016/j.cherd.2019.04.031.

Lang, Y.D., Biegler, L.T., 2002. Distributed stream method for tray optimization. AIChE Journal 48, 582-595. doi:10.1002/aic.690480315.

Lewis, W.K., 1936. Rectification of binary mixtures. Industrial \& Engineering Chemistry 28, 399-402. doi:10.1021/ie50316a005.

Merchan, V.A., Esche, E., Fillinger, S., Tolksdorf, G., Wozny, G., 2015. Computer-aided process and plant development. a review of common software tools and methods and comparison against an integrated collaborative approach. Chemie Ingenieur Technik 88, 50-69. doi:10.1002/cite. 201500099.

Process Systems Enterprise, 1997-2018. gPROMS. URL: www. psenterprise.com/gproms.

Raghunathan, A.U., Biegler, L.T., 2003. Mathematical programs with equilibrium constraints (MPECs) in process engineering. Computers \& Chemical Engineering 27, 1381-1392. doi:10.1016/s0098-1354(03)00092-9.

Raghunathan, A.U., Diaz, M.S., Biegler, L.T., 2004. An MPEC formulation 
for dynamic optimization of distillation operations. Computers \& Chemical Engineering 28, 2037-2052. doi:10.1016/j.compchemeng.2004.03.015.

Reepmeyer, F., Repke, J.U., Wozny, G., 2003. Analysis of the start-up process for reactive distillation. Chemical Engineering \& Technology 26, 8186. doi:10.1002/ceat. 200390012 .

Reepmeyer, F., Repke, J.U., Wozny, G., 2004. Time optimal start-up strategies for reactive distillation columns. Chemical Engineering Science 59, 4339-4347. doi:10.1016/j.ces.2004.06.029.

Ruiz, C., Cameron, I., Gani, R., 1988. A generalized dynamic model for distillation columns - III. study of startup operations. Computers \& Chemical Engineering 12, 1-14. doi:10.1016/0098-1354(88)85001-4.

Sahlodin, A.M., Watson, H.A.J., Barton, P.I., 2016. Nonsmooth model for dynamic simulation of phase changes. AIChE Journal 62, 3334-3351. doi:10.1002/aic.15378.

Seifert, T., Lesniak, A.K., Sievers, S., Schembecker, G., Bramsiepe, C., 2014. Capacity flexibility of chemical plants. Chemical Engineering \& Technology 37, 332-342. doi:10.1002/ceat.201300635.

Staak, D., Morillo, A., Schiffmann, P., Repke, J.U., Wozny, G., 2011. Safety assessment on distillation columns: From shortcut methods and heuristics to dynamic simulation. AIChE Journal 57, 458-472. doi:10.1002/aic. 12270 .

Staudt, P.B., de Pelegrini Soares, R., Secchi, A.R., 2007. Dynamic simulation 
of reactive distillation processes to predict start-up behavior. IFAC Proceedings Volumes 40, 285-290. doi:10.3182/20070606-3-mx-2915.00095.

Stichlmair, J., 2010a. Distillation, 1. Fundamentals in: Ullmann's Encyclopedia of Industrial Chemistry. Wiley-VCH Verlag GmbH \& Co. KGaA. doi:10.1002/14356007.b03_04.pub2.

Stichlmair, J., 2010b. Distillation, 2. Equipment in: Ullmann's Encyclopedia of Industrial Chemistry. Wiley-VCH Verlag GmbH \& Co. KGaA. doi:10 . 1002/14356007.008_001.

Tran, T., Repke, J.U., Wozny, G., 2002. Dynamic model for start-up simulation of threephase distillation column, in: 15th International Congress of Chemical and Process Engineering (CHISA).

VDI (Ed.), 2013. VDI-Wärmeatlas. Springer Vieweg.

Wang, L., Li, P., Wozny, G., Wang, S., 2003. A startup model for simulation of batch distillation starting from a cold state. Computers \& Chemical Engineering 27, 1485-1497. doi:10.1016/s0098-1354(03)00094-2.

Wendt, M., Königseder, R., Li, P., Wozny, G., 2003. Theoretical and experimental studies on startup strategies for a heat-integrated distillation column system. Chemical Engineering Research and Design 81, 153-161. doi:10.1205/026387603321158311.

Wijn, E., 1998. On the lower operating range of sieve and valve trays. Chemical Engineering Journal 70, 143-155. doi:10.1016/s0923-0467(98) 00089-x. 
Zuiderweg, F., 1982. Sieve trays. Chemical Engineering Science 37, 14411464. doi:10.1016/0009-2509(82)80001-8. 


\section{Nomenclature}

\section{Greek Symbols}

\begin{tabular}{|c|c|}
\hline$\Delta P$ & Pressure difference \\
\hline$\Delta T$ & Temperature difference \\
\hline$\Delta h$ & Enthalpy difference \\
\hline$\Delta h A$ & Parameter A for heat of vaporization \\
\hline$\Delta h B$ & Parameter B for heat of vaporization \\
\hline$\Delta h A$ & Enthalpy of vaporization parameter A \\
\hline$\Delta h B$ & Enthalpy of vaporization parameter B \\
\hline$\Phi$ & Phase ratio \\
\hline$\Theta$ & Generalized max operator \\
\hline$\Omega$ & Weeping parameter \\
\hline$\Upsilon$ & Parameter activating total reflux \\
\hline$\alpha$ & Heat transfer coefficient / Separation factor \\
\hline$\delta$ & Diameter \\
\hline$\epsilon$ & Small number \\
\hline$\gamma$ & Sigmoidal for level \\
\hline$\lambda$ & Thickness \\
\hline$\nu$ & Kinematic viscosity \\
\hline$\phi$ & Weir angle \\
\hline$\pi$ & Parameter in froth density and pi \\
\hline$\psi$ & Sigmoidal for temperature \\
\hline$\rho$ & Density \\
\hline$\sigma$ & Surface tension \\
\hline$\sigma A$ & Surface tension parameter A \\
\hline
\end{tabular}




$\begin{array}{cl}\sigma B & \text { Surface tension parameter B } \\ \theta & \text { Generalized sigmoidal } \\ \varphi & \text { Free surface ratio } \\ \xi & \text { Drag coefficient }\end{array}$

\section{Latin Symbols}

$\begin{array}{cl}A & \text { Area } \\ \text { Ant } A & \text { Antoine parameter A } \\ \text { AntB } & \text { Antoine parameter B } \\ \text { AntC } & \text { Antoine parameter C } \\ \text { AntD } & \text { Antoine parameter D } \\ \text { AntE } & \text { Antoine parameter E } \\ C & \text { Constant } \\ C P A & \text { Parameter in cp polynomial } \\ C P B & \text { Parameter in cp polynomial } \\ C P C & \text { Parameter in cp polynomial } \\ D & \text { Diameter } \\ E & \text { Efficiency } \\ F & \text { Flow / F factor } \\ H & \text { Height / tray spacing } \\ H U & \text { Hold-up } \\ K & \text { Velocity factor; proportional controller parameter } \\ L & \text { Level / length } \\ M & \text { Molecular weight } \\ P & \text { Pressure } \\ Q & \text { Heat duty }\end{array}$




\begin{tabular}{|c|c|}
\hline$R$ & Universal gas constant \\
\hline$R R$ & Reflux ratio \\
\hline$S R$ & Stream ratio \\
\hline$T$ & Temperature \\
\hline$U$ & Internal energy \\
\hline$V$ & Volume \\
\hline$V A$ & Volume parameter \\
\hline$V B$ & Volume parameter \\
\hline$V C$ & Volume parameter \\
\hline$X$ & Weir length ratio \\
\hline$Y$ & Weir height ratio \\
\hline$a$ & Parameter A in entrainment correlation \\
\hline$b$ & Parameter B in entrainment correlation \\
\hline$c$ & Heat capacity \\
\hline$e$ & Entrainment factor \\
\hline$g$ & Gravitational acceleration \\
\hline$h$ & Enthalpy / height \\
\hline$m$ & Mass \\
\hline sign & Flow direction variable \\
\hline$t$ & Time \\
\hline$v$ & Molar volume \\
\hline$w$ & Superficial velocity \\
\hline$x$ & Mole fraction \\
\hline$y$ & Binary variable (fixed) \\
\hline
\end{tabular}




\begin{tabular}{|c|c|}
\hline$c \in 1 \ldots N C$ & Index of components: $1=$ benzene, $2=$ toluene \\
\hline$d c \in 1 \ldots N D C$ & Index of downcomers \\
\hline$t \in 1 \ldots N T$ & Index of trays \\
\hline \multicolumn{2}{|l|}{ Subscripts } \\
\hline $\mathrm{C}$ & Critical \\
\hline $\mathrm{CON}$ & Condenser \\
\hline corner & of a corner \\
\hline $\mathrm{RD}$ & Reflux drum \\
\hline active & Active \\
\hline $\mathrm{cl}$ & Clear liquid \\
\hline column & Column \\
\hline dist & Distillate \\
\hline $\mathrm{f}$ & Formation \\
\hline froth & Froth \\
\hline ow & Over weir \\
\hline $\mathrm{p}$ & Constant pressure \\
\hline reboiler & Reboiler \\
\hline ref & Reference \\
\hline tube & of a tube \\
\hline wall & Wall \\
\hline weir & Weir \\
\hline \multicolumn{2}{|l|}{ Superscripts } \\
\hline $\mathrm{CON}$ & Condenser \\
\hline $\mathrm{E}$ & Entrainment \\
\hline$L$ & Liquid \\
\hline
\end{tabular}




$\begin{array}{cl}\text { SP } & \text { Setpoint } \\ V & \text { Vapor } \\ \text { actual } & \text { Vapor-liquid } \\ \text { back } & \text { Variable obtained via max operator } \\ \text { control } & \text { used for control } \\ \text { dc } & \text { Downcomer } \\ \text { equi } & \text { Equilibrium } \\ \text { feed } & \text { Feed } \\ \text { flow } & \text { Flow } \\ \text { loss } & \text { Loss } \\ \text { min } & \text { Minimum } \\ \text { tray } & \text { Tray } \\ \text { weep } & \text { Weeping }\end{array}$




\section{Supplementary material}

Table 11: Units in this model formulation.

\begin{tabular}{|c|c|}
\hline Variable type & Unit \\
\hline Areas & $\mathrm{m}^{2}$ \\
\hline Densities & $\mathrm{kg} \mathrm{m}^{-3}$ \\
\hline Energies/enthalpies & $\mathrm{kJ}$ \\
\hline $\mathrm{F}$ factors & $\mathrm{Pa}^{0.5}$ \\
\hline Flows & $\mathrm{mols}^{-1}$ \\
\hline Heat capacities & $\mathrm{kJ} \mathrm{mol}^{-1} \mathrm{~K}^{-1}$ or $\mathrm{kJ} \mathrm{kg}^{-1} \mathrm{~K}^{-1}$ \\
\hline Heat transfer coefficients & $\mathrm{kW} \mathrm{m} \mathrm{m}^{-2} \mathrm{~K}^{-1}$ \\
\hline Holdups & mol \\
\hline Kinmatic viscosities & $\mathrm{m}^{2} \mathrm{~s}^{-1}$ \\
\hline Levels, heights, and lengths & $\mathrm{m}$ \\
\hline Masses & $\mathrm{kg}$ \\
\hline Molar volumes & $\mathrm{m}^{3} \mathrm{~mol}^{-1}$ \\
\hline Molecular weights & $\mathrm{kg} \mathrm{mol}^{-1}$ \\
\hline Powers & $\mathrm{kW}$ \\
\hline Pressures & bar \\
\hline Surface tensions & $\mathrm{N} \mathrm{m}^{-1}$ \\
\hline Temperatures & $\mathrm{K}$ \\
\hline Velocity factors & $\mathrm{m} \mathrm{s}^{-1}$ \\
\hline Volume flows & $\mathrm{m}^{3} \mathrm{~s}^{-1}$ \\
\hline Volumes & $\mathrm{m}^{3}$ \\
\hline
\end{tabular}




\section{Condenser}

$$
\begin{gathered}
0=F_{t=1}^{V}+F_{t=1}^{L, E}-F_{C O N}^{L} \\
P_{C O N}=\sum_{c=1}^{N C} x_{C O N, c} \cdot P_{C O N, c}^{V L} \\
P_{C O N, c}^{V L}=\exp \left(A n t A_{c}+\frac{A n t B_{c}}{T_{C O N}^{V L}}+A n t C_{c} \cdot \ln \left(T_{C O N}^{V L}\right)+A n t D_{c} \cdot\left(T_{C O N}^{V L}\right)^{A n t E_{c}}\right) \cdot(10)^{-5} \\
x_{C O N, c}=\psi_{t=1} \cdot\left(\Phi \cdot x_{t=1, c}^{V}+(1-\Phi) \cdot x_{t=1, c}^{L}\right)+\left(1-\psi_{t=1}\right) \cdot \sum_{t=1}^{N T} x_{t, c}^{f e e d} \cdot y_{t}^{f e e d} \\
\left.+\frac{C P B_{c}^{L}}{2} \cdot\left(\left(T_{C O N}\right)^{2}-\left(T_{C O N}^{V L}\right)^{2}\right)+\frac{C P C_{c}^{L}}{3} \cdot\left(\left(T_{C O N}\right)^{3}-\left(T_{C O N}^{V L}\right)^{3}\right)\right) \\
h_{t=0}^{L}=\sum_{C=1}^{N C} x_{C O N, c} \cdot\left(h_{C O N, c}^{V}-\Delta h_{C O N, c}^{V L}+C P A_{c}^{L} \cdot\left(T_{C O N}-T_{C O N}^{V L}\right)\right. \\
\left(F_{t=1}^{V}+F_{t=1}^{L, E}\right) \cdot \Phi=F_{t=1}^{V} \\
Q_{C O N}+F_{t=1}^{V} \cdot h_{t=1}^{V}+F_{t=1}^{L, E} \cdot h_{t=1}^{L}-F_{C O N}^{L} \cdot h_{t=0}^{L} \\
\left(60 T_{C O N}\right.
\end{gathered}
$$




$$
\begin{gathered}
h_{C O N, c}^{V}=\Delta h_{f, c}+\frac{C P A_{c}}{2} \cdot\left(\left(T_{C O N}^{V L}\right)^{2}-\left(T_{r e f}\right)^{2}\right)+C P B_{c} \cdot\left(T_{C O N}^{V L}-T_{r e f}\right) \\
\Delta h_{C O N, c}^{V L}=\Delta h A_{c} \cdot\left(1-\frac{T_{C O N}^{V L}}{T_{C, c}}\right)^{\Delta h B_{c}}
\end{gathered}
$$

Reflux drum

$$
\begin{aligned}
& \frac{\mathrm{d} H U_{R D, c}}{\mathrm{dt}}=F_{C O N}^{L} \cdot x_{C O N, c}-F_{t=0}^{L} \cdot x_{t=0, c}^{L}-F_{d i s t} \cdot x_{t=0, c}^{L} \\
& \sum_{c=1}^{N C} H U_{R D, c}=H U_{R D} \\
& H U_{R D} \cdot x_{t=0, c}^{L}=H U_{R D, c} \\
& F_{\text {dist }}=\left(F_{\text {dist }}^{S P}+K_{\text {dist }} \cdot\left(L_{R D}^{L}-L_{R D}^{L, S P}\right)\right) \cdot \gamma_{R D} \\
& F_{t=0}^{L}=\left(F_{t=0}^{L, S P}+K_{t=0} \cdot\left(\left(\sum_{t=1}^{N T} y_{R D, t}^{\text {control }} \cdot T_{t}\right)-T_{R D}^{S P}\right) \cdot \Upsilon\right) \cdot \gamma_{R D} \\
& \gamma_{R D}=\frac{1}{2}+\frac{1}{2} \cdot \frac{L_{R D}^{L}-L_{R D}^{\min }}{\sqrt{\left(L_{R D}^{L}-L_{R D}^{\min }\right)^{2}+(10)^{-10}}} \\
& V_{R D}=\frac{\pi}{4} \cdot\left(D_{R D}\right)^{2} \cdot L_{R D} \\
& V_{R D}^{L}=H U_{R D} \cdot v_{R D}^{L}
\end{aligned}
$$




$$
\begin{gathered}
V_{R D}^{L}=V A_{R D} \cdot\left(L_{R D}^{L}\right)^{3}+V B_{R D} \cdot\left(L_{R D}^{L}\right)^{2}+V C_{R D} \cdot L_{R D}^{L} \\
F_{\text {dist }} \cdot R R=F_{t=0}^{L}
\end{gathered}
$$

Trays

$$
\begin{aligned}
\frac{\mathrm{d} H U_{t, c}}{\mathrm{dt}} & =F_{t}^{\text {feed }} \cdot x_{t, c}^{\text {feed }} \cdot y_{t}^{\text {feed }}+y_{C O N, t} \cdot\left(F_{t=0}^{L}+(1-\Upsilon) \cdot F_{\text {dist }}\right) \cdot x_{t=0, c}^{L} \\
& +\left(1-y_{C O N, t}\right) \cdot\left(F_{t-1}^{L, \text { weep }, \text { actual }} \cdot x_{t-1, c}^{L}+F_{d c=t-1}^{L, \text { actual }} \cdot x_{d c=t-1, c}^{L}-F_{t}^{L, \text { back,actual }} \cdot x_{t, c}^{L}\right) \\
& +F_{t+1}^{V} \cdot x_{t+1, c}^{V}+F_{t+1}^{L, E} \cdot x_{t+1, c}^{L}-\left(F_{\text {weir }, t}^{L}+F_{t}^{L, \text { weep }, \text { actual }}\right) \cdot x_{t, c}^{L}-F_{t}^{V} \cdot x_{t, c}^{V}-F_{t}^{L, E} \cdot x_{t, c}^{L}
\end{aligned}
$$

$$
x_{t, c}^{V, e q u i}=x_{t, c}^{L} \cdot \frac{P_{t, c}^{V L}}{P_{t}}
$$$$
\sum_{c=1}^{N C} x_{t, c}^{L}=1
$$

$$
H U_{t, c}=H U_{t}^{L} \cdot x_{t, c}^{L}+H U_{t}^{V, a c t u a l} \cdot x_{t, c}^{V}
$$

$$
\begin{aligned}
\frac{\mathrm{d} U_{t}}{\mathrm{dt}} & =-Q_{t}^{\text {loss }}+F_{t}^{f e e d} \cdot h_{t}^{\text {feed }} \cdot y_{t}^{\text {feed }}+y_{C O N, t} \cdot\left(F_{t=0}^{L}+(1-\Upsilon) \cdot F_{\text {dist }}\right) \cdot h_{t=0}^{L} \\
& +\left(1-y_{C O N, t}\right) \cdot\left(F_{t-1}^{L, \text { weep }, \text { actual }} \cdot h_{t-1}^{L}+F_{d c=t-1}^{L, \text { actual }} \cdot h_{t-1}^{L}-F_{t}^{L, \text { back, actual }} \cdot h_{t}^{L}\right) \\
& +F_{t+1}^{V} \cdot h_{t+1}^{V}+F_{t+1}^{L, E} \cdot h_{t+1}^{L}-\left(F_{\text {weir }, t}^{L}+F_{t}^{L, \text { weep }, \text { actual }}\right) \cdot h_{t}^{L}-F_{t}^{V} \cdot h_{t}^{V}-F_{t}^{L, E} \cdot h_{t}^{L}
\end{aligned}
$$




$$
\begin{aligned}
& P_{t}=P_{t-1}+\Delta P_{t}^{\text {tray }} \\
& U_{t}=H U_{t}^{L} \cdot h_{t}^{L}+H U_{t}^{V, a c t u a l} \cdot h_{t}^{V}-P_{t} \cdot V^{\text {tray }} \cdot(10)^{2}+m^{\text {tray }} \cdot c^{\text {tray }} \cdot\left(T_{t}-T_{r e f}\right) \\
& A_{\text {active }} \cdot h_{c l, t}=H U_{t}^{L} \cdot v_{t}^{L} \\
& h_{c l, t}=\rho_{\text {froth }, t} \cdot\left(h_{\text {weir }}+h_{o w, t}\right) \\
& \rho_{\text {froth }, t}=\exp \left(\pi_{p i=1} \cdot\left(\frac{K_{t}+\sqrt{\left(K_{t}\right)^{2}+\epsilon}}{2}\right)^{\pi_{p i=2}}\right) \\
& K_{t} \cdot \sqrt{\rho_{t}^{L}-\rho_{t}^{V}}=F_{t} \\
& F_{t}=w_{t}^{V} \cdot \sqrt{\frac{\rho_{t}^{V}+\sqrt{\left(\rho_{t}^{V}\right)^{2}+\epsilon}}{2}} \\
& F_{t}^{V} \cdot v_{t}^{V}=A_{\text {column }} \cdot w_{t}^{V} \\
& \left(\frac{h_{\text {ow }, t}^{\text {actual }}}{\text { WeirParam }}\right)^{\frac{3}{2}} \cdot \rho_{\text {froth }, t} \cdot L_{\text {weir }}=V_{\text {weir }, t}^{L, f l o w} \\
& h_{\text {ow }, t}^{\text {actual }}=\frac{h_{o w, t}+\sqrt{\left(h_{o w, t}\right)^{2}+(10)^{-10}}}{2} \\
& F_{\text {weir }, t}^{L}+F_{t}^{L, \text { weep }, \text { actual }}=F_{t}^{L}
\end{aligned}
$$




$$
\begin{gathered}
V_{\text {weir,t }}^{L, \text { flow }}=F_{\text {weir }, t}^{L} \cdot v_{t}^{L} \\
v_{t}^{V} \cdot H U_{t}^{V}=\left(V^{\text {tray }}-H U_{t}^{L} \cdot v_{t}^{L}\right) \\
\psi_{t} \cdot H U_{t}^{V}=H U_{t}^{V, a c t u a l} \\
\Delta P_{t}^{\text {tray }}=\left(\rho_{t-1}^{L} \cdot g \cdot h_{c l, t-1}+\operatorname{sign}_{t} \cdot \frac{\xi}{2} \cdot\left(F_{t}\right)^{2}\right) \cdot(10)^{-5} \cdot \psi_{t} \cdot\left(1-y_{C O N, t}\right) \\
+\operatorname{sign}_{t} \cdot\left(128 \cdot \frac{\nu \cdot F_{t}^{V} \cdot v_{t}^{V} \cdot L_{t u b e}}{\pi \cdot\left(\delta_{t u b e}\right)^{4}}+3 \cdot 8 \cdot \xi_{\text {column }} \cdot \frac{\rho_{t}^{V}}{\left(\delta_{t u b e}\right)^{4}} \cdot\left(\frac{F_{t}^{V} \cdot v_{t}^{V}}{\pi}\right)^{2}\right) \cdot(10)^{-5} \cdot \psi_{t} \cdot y_{C O N, t}
\end{gathered}
$$

$$
\begin{gathered}
\operatorname{sign}_{t}=\frac{F_{t}^{V}}{\sqrt{\left(F_{t}^{V}\right)^{2}+(10)^{-8}}} \\
M_{t}^{L}=\sum_{c=1}^{N C} x_{t, c}^{L} \cdot M_{c} \\
M_{t}^{V}=\sum_{c=1}^{N C} x_{t, c}^{V} \cdot M_{c} \\
M_{t}^{L}=\rho_{t}^{L} \cdot v_{t}^{L} \\
M_{t}^{V}=\rho_{t}^{V} \cdot v_{t}^{V}
\end{gathered}
$$$$
P_{t} \cdot v_{t}^{V} \cdot(10)^{5}=R \cdot T_{t}
$$ 


$$
\begin{gathered}
P_{t, c}^{V L}=\exp \left(A n t A_{c}+\frac{A n t B_{c}}{T_{t}}+A n t C_{c} \cdot \ln \left(T_{t}\right)+A n t D_{c} \cdot\left(T_{t}\right)^{A n t E_{c}}\right) \cdot(10)^{-5} \\
h_{t}^{V}=\sum_{c=1}^{N C} x_{t, c}^{V} \cdot h_{t, c}^{V} \\
h_{t, c}^{V}=\Delta h_{f, c}+\frac{C P A_{c}}{2} \cdot\left(\left(T_{t}\right)^{2}-\left(T_{r e f}\right)^{2}\right)+C P B_{c} \cdot\left(T_{t}-T_{r e f}\right) \\
h_{t}^{L}=\sum_{c=1}^{N C} x_{t, c}^{L} \cdot\left(h_{t, c}^{V}-\Delta h_{t, c}^{V L}\right) \\
\Delta h_{t, c}^{V L}=\Delta h A_{c} \cdot\left(1-\frac{T_{t}}{T_{C, c}}\right)^{\Delta h B_{c}}
\end{gathered}
$$

$$
\begin{gathered}
\Delta h_{t, c}^{V L, f e e d}=\Delta h A_{c} \cdot\left(1-\frac{T^{\text {feed }}}{T_{C, c}}\right)^{\Delta h B_{c}} \\
P_{t}=\sum_{c=1}^{N C} x_{t, c}^{L} \cdot P_{t, c}^{V}
\end{gathered}
$$

$$
P_{t, c}^{V}=\exp \left(A n t A_{c}+\frac{A n t B_{c}}{T_{t}^{V L}}+A n t C_{c} \cdot \ln \left(T_{t}^{V L}\right)+A n t D_{c} \cdot\left(T_{t}^{V L}\right)^{A n t E_{c}}\right) \cdot(10)^{-5}
$$




$$
\begin{aligned}
& \psi_{t}=0.5+0.5 \cdot \frac{T_{t}-T_{t}^{V L}-(10)^{-4}}{\sqrt{\left(T_{t}-T_{t}^{V L}-(10)^{-4}\right)^{2}+(10)^{-10}}} \\
& \left(T_{t}^{V L}-T_{t}\right) \cdot \psi_{t}+\left(1-\psi_{t}\right) \cdot F_{t}^{V}=0 \\
& Q_{t}^{\text {loss }}=\alpha_{t} \cdot A^{\text {tray }} \cdot\left(T_{t}-T_{\text {ref }}\right) \\
& m^{\text {tray }}=\rho^{\text {tray }} \cdot\left(\left(A_{\text {active }}+A^{d c}\right) \cdot h^{\text {tray }}+\frac{\pi}{4} \cdot\left(\left(D_{\text {column }}+2 \cdot \lambda_{\text {wall }}\right)^{2}-\left(D_{\text {column }}\right)^{2}\right) \cdot H\right) \\
& A_{\text {column }}=\frac{\pi}{4} \cdot\left(D_{\text {column }}\right)^{2} \\
& A^{d c}=\frac{\left(D_{\text {column }}\right)^{2}}{8} \cdot\left(\frac{\phi \cdot \pi}{180}-\sin \left(\frac{\phi \cdot \pi}{180}\right)\right) \\
& A_{\text {active }}=A_{\text {column }}-2 \cdot A^{d c} \\
& V^{\text {tray }}=A_{\text {active }} \cdot H \\
& A^{\text {tray }}=\pi \cdot\left(D_{\text {column }}+2 \cdot \lambda_{\text {wall }}\right) \cdot H \\
& X_{\text {weir }} \cdot D_{\text {column }}=L_{\text {weir }} \\
& \sin \left(\frac{\phi \cdot \pi}{180 \cdot 2}\right)=X_{w e i r}
\end{aligned}
$$




$$
\begin{gathered}
x_{t, c}^{V}=\left(E_{t} \cdot\left(x_{t, c}^{V, e q u i}-x_{t+1, c}^{V}\right)+x_{t+1, c}^{V}\right) \cdot \psi_{t} \\
F_{t}^{L, E} \cdot M_{t}^{L}=e_{t} \cdot F_{t}^{V} \cdot M_{t}^{V}
\end{gathered}
$$

Sub-system Murphree efficiencies

$$
\begin{gathered}
E_{t} \cdot\left(\lambda_{t}+(10)^{-3}-1\right)=\left(\left(\lambda_{t}+(10)^{-3}\right)^{\left.E_{\text {column }}-1\right)}\right. \\
\lambda_{t}=m_{t} \cdot S R_{t} \\
m_{t} \cdot\left(1+\left(\alpha_{t}^{e q u i}-1\right) \cdot x_{t, c=1}^{L}\right)^{2}=\alpha_{t}^{e q u i} \\
S R_{t} \cdot\left(F_{t-1}^{L}+(10)^{-3}\right)=F_{t+1}^{V} \\
P_{t, c=2}^{V L} \cdot \alpha_{t}^{e q u i}=P_{t, c=1}^{V L}
\end{gathered}
$$

Sub-system weeping

$$
\begin{gathered}
F_{t}^{L, \text { weep }} \cdot v_{t}^{L}=\Omega_{t}^{\text {actual }} \cdot A_{\text {active }} \cdot \varphi \cdot \sqrt{2 \cdot g \cdot h_{c l, t}^{\text {weep }}} \\
F_{t}^{L, \text { weep }, \text { actual }}=F_{t}^{L, \text { weep }} \cdot 0.5 \cdot\left(1+\frac{h_{c l, t}-h_{c l}^{S P}}{\sqrt{\left(h_{c l, t}-h_{c l}^{S P}\right)^{2}+(10)^{-10}}}\right) \\
\Omega_{t}=\operatorname{Par}_{\text {weep }=3} \cdot \exp \left(-\operatorname{Par}_{\text {weep }=2} \cdot \frac{F_{t+1}}{\varphi}+\operatorname{Par}_{\text {weep }=1}\right)
\end{gathered}
$$




$$
\begin{aligned}
& \Omega_{t}^{\text {actual }}=\frac{\Omega_{t}+1-\sqrt{\left(\Omega_{t}-1\right)^{2}+\epsilon}}{2} \\
& h_{c l, t}^{\text {weep }}=\frac{h_{c l, t}+\sqrt{\left(h_{c l, t}\right)^{2}+(10)^{-10}}}{2}
\end{aligned}
$$

Sub-system entrainment

$\left(e_{t}\right) \cdot\left(\left(H-2.5 \cdot h_{c l, t}\right) \cdot 39.37\right)^{b} \cdot \sum_{c=1}^{N C} x_{t, c}^{L} \cdot \sigma_{t, c} \cdot(10)^{3}=a \cdot\left(\left(w_{t}^{V}+(10)^{-3}\right) \cdot 3.28\right)^{b}$

$$
\sigma_{t, c}=\sigma A_{c} \cdot\left(1-\frac{T_{t}}{T_{C, c}}\right)^{\sigma B_{c}}
$$

\section{Downcomer}

$$
\begin{gathered}
\frac{\mathrm{d} H U_{d c, c}}{\mathrm{dt}}=F_{w e i r, t=d c}^{L} \cdot x_{t=d c, c}^{L}-F_{d c}^{L, a c t u a l} \cdot x_{d c, c}^{L}+F_{t=d c+1}^{L, b a c k, a c t u a l} \cdot x_{t=d c+1, c}^{L} \\
x_{d c, c}^{L} \cdot \sum_{c=1}^{N C} H U_{d c, c}=H U_{d c, c} \\
v_{d c}^{L} \cdot \sum_{c=1}^{N C} H U_{d c, c}=A^{d c} \cdot h_{c l, d c} \\
F_{d c}^{L}=K^{d c} \cdot\left(h_{c l, d c}-h_{c l, t=d c+1}\right) \cdot\left(1-\psi_{t=d c+1}\right) \\
+\frac{1}{v_{d c}^{L}} \cdot \frac{X_{w e i r} \cdot D_{c o l u m n} \cdot Y_{w e i r} \cdot h_{w e i r}}{\sqrt{0.1652}} \cdot \sqrt{h_{d c}^{\text {flow }, \text { actual }}} \cdot \psi_{t=d c+1}
\end{gathered}
$$




$$
F_{t=d c+1}^{L, b a c k}=-K^{d c} \cdot\left(h_{c l, d c}-h_{c l, t=d c+1}\right)
$$

$$
\Delta P_{t=d c+1}^{t r a y}+\rho_{t=d c+1}^{L} \cdot g \cdot h_{c l, t=d c+1} \cdot(10)^{-5}+\rho_{t=d c}^{L} \cdot g \cdot h_{d c}^{f l o w} \cdot(10)^{-5}=\rho_{t=d c}^{L} \cdot g \cdot h_{c l, d c} \cdot(10)^{-5}
$$

$$
\begin{aligned}
h_{d c}^{\text {flow }, \text { actual }} & =\frac{h_{d c}^{\text {flow }}+\sqrt{\left(h_{d c}^{\text {flow }}\right)^{2}+(10)^{-10}}}{2} \\
F_{d c}^{L, \text { actual }} & =\frac{F_{d c}^{L}+\sqrt{\left(F_{d c}^{L}\right)^{2}+(10)^{-10}}}{2}
\end{aligned}
$$

$$
F_{t=d c+1}^{L, b a c k, a c t u a l}=\frac{F_{t=d c+1}^{L, b a c k}+\sqrt{\left(F_{t=d c+1}^{L, b a c k}\right)^{2}+(10)^{-10}}}{2}+h_{c l, d c} \cdot 0
$$

\section{Reboiler}

$$
\begin{gathered}
\frac{\mathrm{d} H U_{t=N T+1, c}}{\mathrm{dt}}=F_{t=N T}^{L} \cdot x_{t=N T, c}^{L}-F_{t=N T+1}^{V} \cdot x_{t=N T+1, c}^{V}-F_{t=N T+1}^{L} \cdot x_{t=N T+1, c}^{L} \\
-F_{t=N T+1}^{L, E} \cdot x_{t=N T+1, c}^{L} \\
x_{t=N T+1, c}^{V}=x_{t=N T+1, c}^{L} \cdot \frac{P_{t=N T+1, c}^{V L}}{P_{t=N T+1}} \cdot \psi_{t=N T+1} \\
1=\sum_{c=1}^{N C} x_{t=N T+1, c}^{L} \\
H U_{t=N T+1, c}=H U_{t=N T+1}^{L} \cdot x_{t=N T+1, c}^{L}+H U_{t=N T+1}^{V, a c t u a l} \cdot x_{t=N T+1, c}^{V}
\end{gathered}
$$




$$
\frac{\mathrm{d} U_{t=N T+1}}{\mathrm{dt}}=Q_{\text {reboiler }}+F_{t=N T}^{L} \cdot h_{t=N T}^{L}-F_{t=N T+1}^{V} \cdot h_{t=N T+1}^{V}-F_{t=N T+1}^{L} \cdot h_{t=N T+1}^{L}-Q_{\text {reboiler }}^{\text {loss }}
$$

$$
P_{t=N T+1}=P_{t=N T}+\Delta P_{t=N T+1}^{\text {tray }}
$$

$$
\begin{aligned}
U_{t=N T+1} & =H U_{t=N T+1}^{L} \cdot h_{t=N T+1}^{L}+H U_{t=N T+1}^{V, \text { actual }} \cdot h_{t=N T+1}^{V} \\
& -P_{t=N T+1} \cdot V_{\text {reboiler }} \cdot(10)^{2}+m_{\text {reboiler }} \cdot c_{\text {reboiler }} \cdot\left(T_{t=N T+1}-T_{\text {ref }}\right)
\end{aligned}
$$

$$
\begin{gathered}
A_{\text {active }} \cdot h_{c l, t=N T+1}=H U_{t=N T+1}^{L} \cdot v_{t=N T+1}^{L} \\
h_{o w, t=N T+1}=h_{c l, t=N T+1}-h_{\text {reboiler }} \\
h_{\text {ow }, t=N T+1}^{\text {actual }}=\frac{h_{\text {ow }, t=N T+1}+\sqrt{\left(h_{o w, t=N T+1}\right)^{2}+(10)^{-10}}}{2} \\
\left(\frac{h_{\text {ow }, t=N T+1}^{\text {actual }}}{W e i r P a r a m}\right)^{\frac{3}{2}} \cdot L_{\text {weir }}=V_{w e i r, t=N T+1}^{L, f l o w} \\
V_{\text {reboiler }, t=N T+1}^{L, f l o w}=F_{t=N T+1}^{L} \cdot v_{t=N T+1}^{L} \\
H U_{t=N T+1}^{L} \cdot v_{t=N T+1}^{L}+H U_{t=N T+1}^{V} \cdot v_{t=N T+1}^{V} \\
H U_{t=N T+1}^{V, a c t u a l}=\psi_{t=N T+1} \cdot H U_{t=N T+1}^{V}
\end{gathered}
$$




$$
\begin{aligned}
& \Delta P_{t=N T+1}^{t r a y}=\left(\rho_{t=N T}^{L} \cdot g \cdot h_{c l, t=N T}+\operatorname{sign}_{t=N T+1} \cdot \frac{\xi}{2} \cdot\left(F_{t=N T+1}\right)^{2}\right) \cdot(10)^{-5} \\
& \operatorname{sign}_{t=N T+1}=\frac{F_{t=N T+1}^{V}}{\sqrt{\left(F_{t=N T+1}^{V}\right)^{2}+(10)^{-8}}} \\
& F_{t=N T+1} \cdot A_{\text {column }}=F_{t=N T+1}^{V} \cdot v_{t=N T+1}^{V} \cdot \rho_{t=N T+1}^{V} \\
& P_{t=N T+1} \cdot v_{t=N T+1}^{V} \cdot(10)^{5}=R \cdot T_{t=N T+1} \\
& M_{t=N T+1}^{V}=\sum_{c=1}^{N C} x_{t=N T+1, c}^{V} \cdot M_{c} \\
& M_{t=N T+1}^{V}=\rho_{t=N T+1}^{V} \cdot v_{t=N T+1}^{V} \\
& P_{t=N T+1, c}^{V L}=\exp \left(A n t A_{c}+\frac{A n t B_{c}}{T_{t=N T+1}}+A n t C_{c} \cdot \ln \left(T_{t=N T+1}\right)+A n t D_{c} \cdot\left(T_{t=N T+1}\right)^{A n t E_{c}}\right) \cdot(10)^{-5} \\
& h_{t=N T+1}^{V}=\sum_{c=1}^{N C} x_{t=N T+1, c}^{V} \cdot h_{t=N T+1, c}^{V} \\
& h_{t=N T+1, c}^{V}=\Delta h_{f, c}+\frac{C P A_{c}}{2} \cdot\left(\left(T_{t=N T+1}\right)^{2}-\left(T_{r e f}\right)^{2}\right)+C P B_{c} \cdot\left(T_{t=N T+1}-T_{r e f}\right) \\
& h_{t=N T+1}^{L}=\sum_{c=1}^{N C} x_{t=N T+1, c}^{L} \cdot\left(h_{t=N T+1, c}^{V}-\Delta h_{t=N T+1, c}^{V L}\right)
\end{aligned}
$$




$$
\begin{aligned}
& \Delta h_{t=N T+1, c}^{V L}=\Delta h A_{c} \cdot\left(1-\frac{T_{t=N T+1}}{T_{C, c}}\right)^{\Delta h B_{c}} \\
& P_{t=N T+1}=\sum_{c=1}^{N C} x_{t=N T+1, c}^{L} \cdot P_{t=N T+1, c}^{V} \\
& P_{t=N T+1, c}^{V}=\exp \left(A n t A_{c}+\frac{A n t B_{c}}{T_{t=N T+1}^{V L}}+A n t C_{c} \cdot \ln \left(T_{t=N T+1}^{V L}\right)+A n t D_{c} \cdot\left(T_{t=N T+1}^{V L}\right)^{A n t E_{c}}\right) \cdot(10)^{-5} \\
& \psi_{t=N T+1}=0.5+0.5 \cdot \frac{T_{t=N T+1}-T_{t=N T+1}^{V L}-(10)^{-4}}{\sqrt{\left(T_{t=N T+1}-T_{t=N T+1}^{V L}-(10)^{-4}\right)^{2}+(10)^{-10}}} \\
& \left(T_{t=N T+1}^{V L}-T_{t=N T+1}\right) \cdot \psi_{t=N T+1}+\left(1-\psi_{t=N T+1}\right) \cdot F_{t=N T+1}^{V}=0 \\
& Q_{\text {reboiler }}=\left(Q_{\text {reboiler }}^{S P}-K_{\text {reboiler }} \cdot\left(\left(\sum_{t=1}^{N T} y_{\text {reboiler }, t}^{\text {control }} \cdot T_{t}\right)-T_{\text {reboiler }}^{S P}\right) \cdot \Upsilon\right) \cdot \gamma_{\text {reboiler }} \\
& Q_{\text {reboiler }}^{\text {loss }}=\alpha_{\text {reboiler }} \cdot \pi \cdot\left(D_{\text {column }}+2 \cdot \lambda_{\text {wall }}\right)^{2} \cdot H_{\text {reboiler }} \cdot\left(T_{t=N T+1}-T_{\text {ref }}\right) \\
& \gamma_{\text {reboiler }}=0.5+0.5 \cdot \frac{h_{c l, t=N T+1}-h_{\text {reboiler }}^{S P}}{\sqrt{\left(h_{c l, t=N T+1}-h_{\text {reboiler }}^{S P}\right)^{2}+(10)^{-5}}} \\
& m_{\text {reboiler }}=\rho^{\text {tray }} \cdot\left(\frac{\pi}{4} \cdot\left(\left(D_{\text {column }}+2 \cdot \lambda_{\text {wall }}\right)^{2}-\left(D_{\text {column }}\right)^{2}\right) \cdot H_{\text {reboiler }}+\lambda_{\text {wall }} \cdot h_{\text {reboiler }} \cdot L_{\text {weir }}+A_{\text {column }} \cdot h^{\text {tray }}\right) \\
& V_{\text {reboiler }}=A_{\text {column }} \cdot H_{\text {reboiler }}
\end{aligned}
$$

